\title{
Chapter 3 \\ Analysis of Radioactive Release \\ from the Fukushima Daiichi \\ Nuclear Power Station
}

\author{
Satoru Tanaka and Shinichiro Kado
}

\begin{abstract}
Basic schemes and databases necessary to assess the radioactive release in severe accidents at nuclear power plants are presented. The approaches include one based on the physical and chemical properties of the core fuel, and another based on the radiation monitor. Trials of the rough evaluation for the severe accident at Fukushima Daiichi nuclear power station are made using both approaches without relying on specialized computer simulations for educational purposes, even though the exact values will be less reliable. The results were compared with the official statements by the authorities for both cases, and confirmed to be nevertheless fairly consistent with each other. This fact implies that these "manual calculation-based" approaches are practically useful, especially for accidents where detailed simulation results have not yet come out, or are still unavailable or ambiguous. Background of the database, such as atmospheric diffusion, flash boiling, and radiological equivalence including dose factor, are described in the appendixes.
\end{abstract}

Keywords Core inventory - Severe accident progression - Radioactive release • Dose assessment $\cdot$ Ground shine $\cdot$ Radiological equivalence

S. Tanaka has retired from the University of Tokyo in September 2014.

\footnotetext{
S. Tanaka $(\varangle)$

Department of Nuclear Engineering and Management, The University of Tokyo,

7-3-1 Hongo, Bunkyo-Ku, Tokyo 113-8656, Japan

e-mail: s-tanaka@n.t.u-tokyo.ac.jp

S. Kado

Institute of Advanced Energy, Kyoto University, Gokasho, Uji, Kyoto 611-0011, Japan

e-mail: kado@iae.kyoto-u.ac.jp
}

J. Ahn et al. (eds.), Reflections on the Fukushima Daiichi Nuclear Accident, DOI 10.1007/978-3-319-12090-4_3 


\subsection{Introduction}

Located at the Fukushima Daiichi (1F) nuclear power station (NPS) are six nuclear power plants. Among them, Units 1, 2, and 3 (referred to hereafter as 1F1, $1 \mathrm{~F} 2$, and $1 \mathrm{~F} 3$, respectively) had major accidents resulting from the earthquake and tsunami on March 11, 2011. Units 1, 2, and 3 encountered station blackout (SBO), i.e., loss of all alternating current (AC) power including emergency diesel generator, back-up battery depletion, and emergency cooling system failure. Response to the accident faced severe difficulties in removing the decay heat of the fuel and oxidization heat of the fuel rods made by Zircaloy (see Chap. 2 of this volume). Finally, core melt of the fuel rods occurred. What was worse, the fuel materials further melted through the reactor pressure vessels (RPVs), which led to a considerable amount of leakage of the radioactive materials to the environment.

Information necessary to evaluate (or even to speculate) the degree of seriousness of the accident seemed to be insufficient, since it was limited, undisclosed, or uncertain, especially in the early stage of the accident. Even under such circumstances, one could only rely on the inventory calculated from the operation history of each unit, together with the physical and chemical properties of the materials, and ambient dose rate monitored by the government, electric power companies, or nuclear facilities in research institutes or in universities. ${ }^{1}$

The purpose of this chapter is thus to introduce some background information for scientific analysis of the release of radioactive materials from the Fukushima Daiichi NPS based on their inventory in the reactor core, mechanisms of the release, and the behavior of the released radionuclide. The state of contamination and decontamination of the area is also briefly mentioned.

\subsection{Methods of Analysis}

\subsubsection{General Concepts for Various Models}

The image of the damage and the pathways of the radioactive materials are shown schematically in Fig. 3.1. These events, together with the leakage of the primary containment vessels (PCVs), caused significant release of radionuclides to the environment.

The real situation was far more complicated. Thermally damaged top-head flanges, cracks in pipe inlets in the PCV, and vent pipes between the PCV and the

\footnotetext{
1 Note that the data evaluated here have considerable ambiguities; thus the authors would like to suggest that readers take them as examples for study of methodology of the analysis from the limited availability of information and data. Indeed, up to now (as of 2014), the data reported by the government, TEPCO, etc., have been frequently updated.
} 


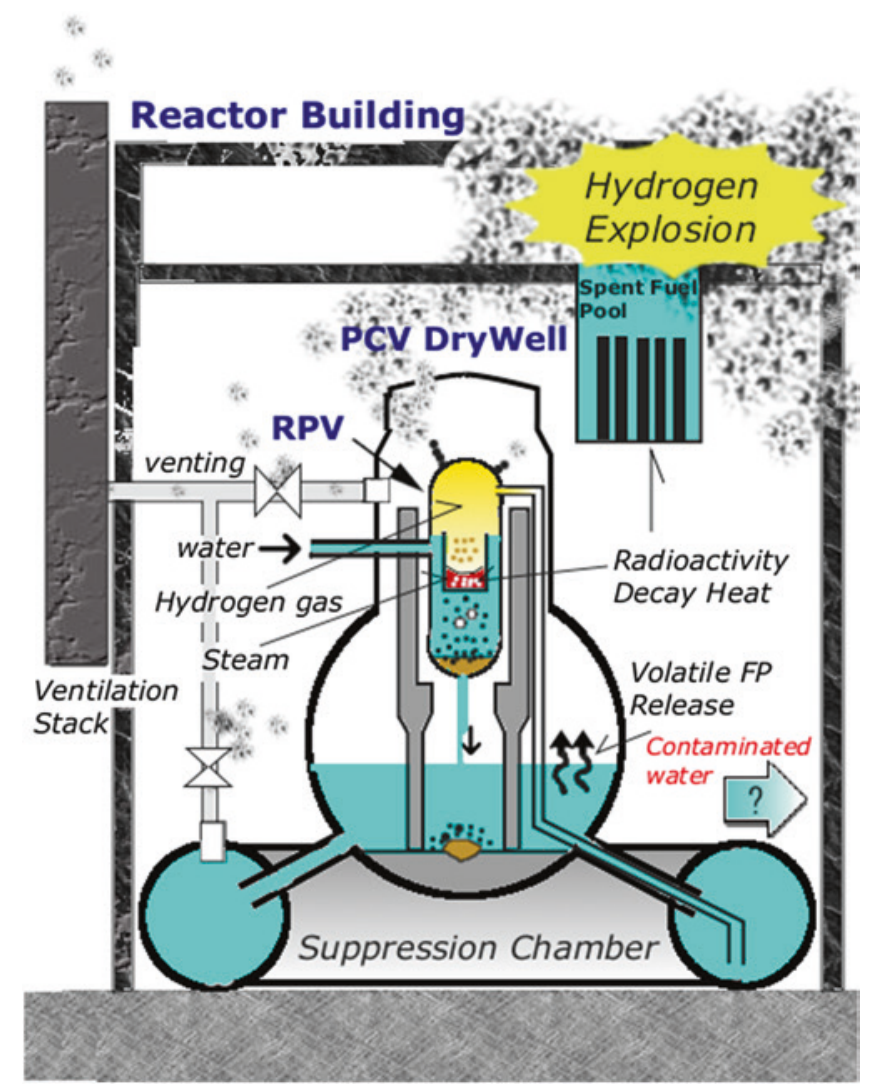

Fig. 3.1 Schematic drawing of the reactor damage and behavior of radioactive materials

suppression chamber (SC) have been regarded as possible leak paths. Indeed, three units exhibited different features of cooling failure (see Chap. 2 of this volume).

Figure 3.2 shows schematically the behavior of radioactive materials in the environment after their release from the reactor facility. In order to assess the direct effects of the radioactive release to the environment, we must make use of the inventory of radionuclides and chemical elements in the fuel just before the accident; release from the fuel at the accident; existence states of radionuclides in the RPV, PCV, and reactor building; release from the stack or reactor building; migration in the atmosphere; contamination of soil; and ambient dose rate from radionuclides in the soil and in the atmosphere.

There are basically two approaches to evaluating the amount of environmental release of radionuclides. One is based on analysis of the physical and chemical conditions of the core fuel. In this approach, a fraction of the released amount is approximated with certain plausible values. The other is based on "radiation mapping" made by monitoring the excess ambient dose rate and/or radioactivity measurement of the contaminated soils. The former is an indirect method because 


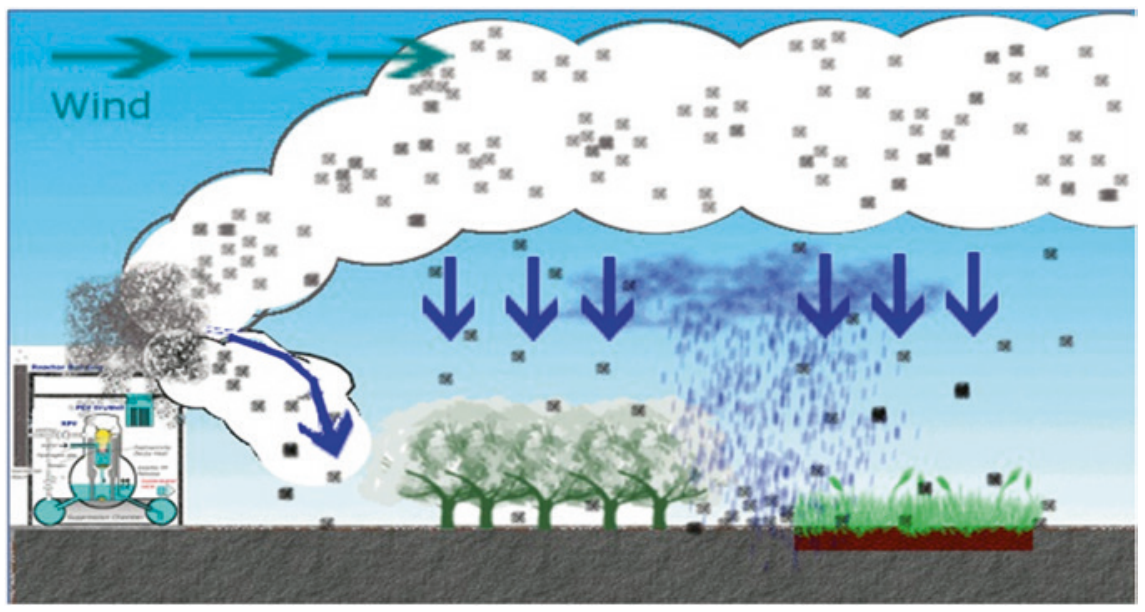

Fig. 3.2 Radioactive materials in the environment

the radioactive species need to be assumed from other information or knowledge. However, in the early stages of the accident it is more convenient than the latter.

\subsubsection{Model 1: Release from Fuel with Known/Assumed Inventory}

Amounts of radionuclides, such as fission products (FPs), uranium (U), plutonium $(\mathrm{Pu})$, and minor actinides (MAs) in the reactor fuel need to be evaluated. Information about the chemical elements is also important for the stoichiometric estimation of the chemical forms of released fission products. This can be calculated with the help of the ORIGEN code [1], which is based on the theory of production and the following radioactive decay of FPs and MAs.

A cause for release of radioactive materials at all reactors was that decay heat of fission products had not been eliminated due to loss of the cooling function. Consequently, the fuel rods were exposed to steam and the fuel and cladding were heated up, which resulted in generation of hydrogen gas by chemical reaction between zirconium and steam above $900{ }^{\circ} \mathrm{C}$. The reaction $\mathrm{Zr}+2 \mathrm{H}_{2} \mathrm{O} \rightarrow \mathrm{ZrO}_{2}+2 \mathrm{H}_{2}$ produces hydrogen, which caused the subsequent hydrogen explosions. It also produces heat because this reaction is exothermic. This heat accelerates the heating of the fuel combined with decay heat. At high temperatures uranium made an eutectic compound with zirconium. The melting point of this eutectic is lower than uranium oxide. Figure 3.3 shows high temperature phenomena of the fuel relating to the core-melt progression $[2,3]$. Some radioactive materials in the fuel soluble in $\mathrm{UO}_{2}$ were released following heating and melting of the fuel. The fraction of released radioactive materials from the heated 


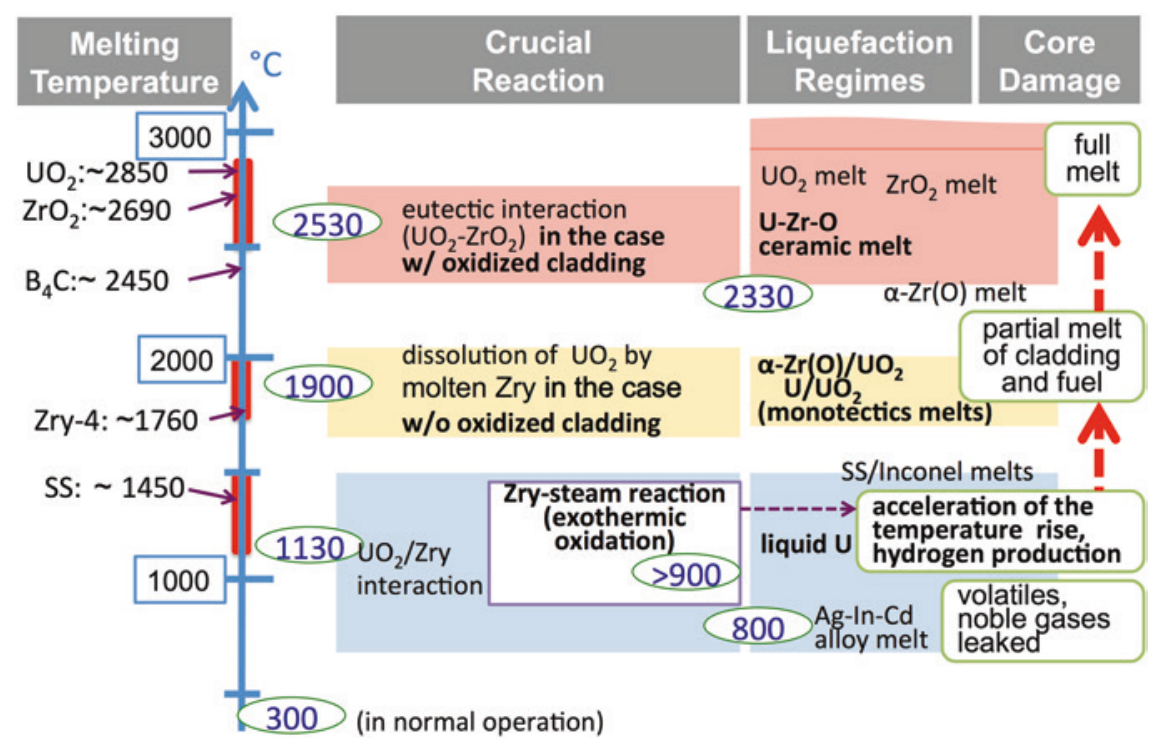

Fig. 3.3 High temperature phenomena in the core $[2,3]$

fuel depends on the vapor pressure (i.e., melting point) and diffusivity in the fuel. These behaviors are strongly dependent on the temperature. A release rate constant $k\left[\mathrm{~min}^{-1}\right]$ as a function of the temperature $T[\mathrm{~K}]$ is given by

$$
k=k_{0} \exp (-Q / R T),
$$

where $Q$ is the activation energy [ $\mathrm{kcal} / \mathrm{mol}$ ], and $R=0.001987 \mathrm{kcal} / \mathrm{mol} K$ the universal gas constant.

Although $Q$ depends on the chemical species, Oak Ridge National Laboratory (ORNL) and others proposed, in their CORSOR-O model [4], to use the common $Q$ of $55 \mathrm{kcal} / \mathrm{mol}$ for all species and the dependence on the species is represented by the empirically corrected $k_{0}$. For example, $k_{0}=12,000 \mathrm{~min}^{-1}$ for $\mathrm{Cs}$ and $\mathrm{Kr}$ while it is $9,600 \mathrm{~min}^{-1}\left[=0.8 \times k_{0}(\mathrm{Cs})\right]$ for I and Te. The results are shown in Fig. 3.4.

Using the CORSOR-O model, the fraction of inventory released from the fuel at time $t$ is obtainable. Taking $\mathrm{Cs}$ as an example for calculation, the fractions of inventory released at $1,800{ }^{\circ} \mathrm{C}$ are: $\mathrm{F}=90 \%$ at $t=2 \mathrm{~h}$; and $F=100 \%$ at $t=4 \mathrm{~h}$.

\subsubsection{Model 2: Codes for Severe Accident Progression Analysis}

Computer codes have been developed to analyze or predict the progression of severe accidents. Modular Accident Analysis Program (MAAP) was developed 
Fig. 3.4 Temperature dependence of release rate constants from $\mathrm{UO}_{2}$ fuel

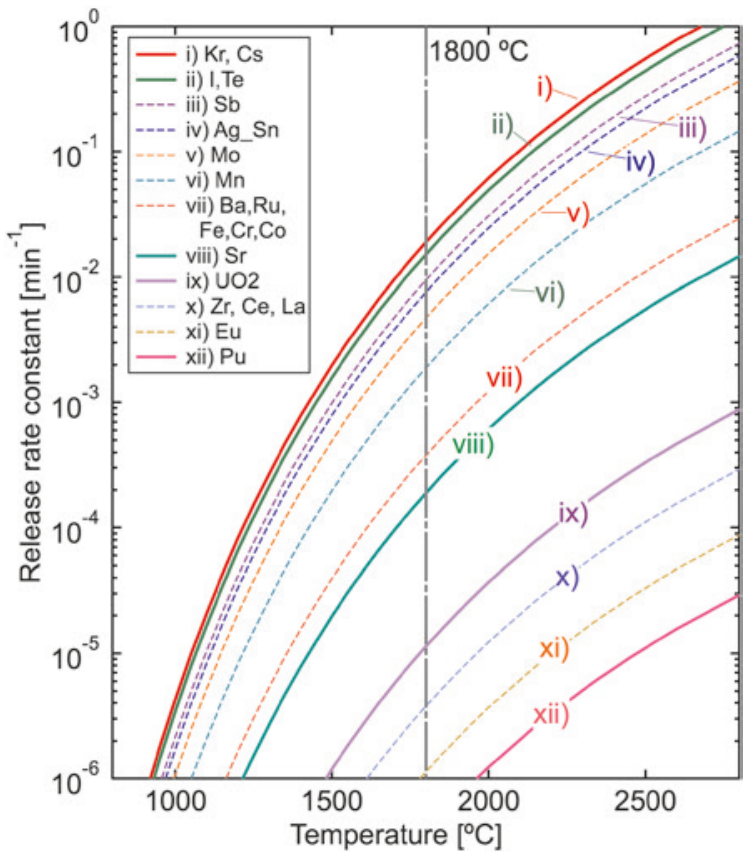

by U.S. industries while MELCOR was developed by the United States Nuclear Regulatory Commission (US NRC) [5].

These codes basically calculate the thermal response of the core, dealing with the entire progression from the initiating event to the radionuclide releases to the environment, which is called the "source term." Therefore, the initial inventory and the release properties for each nuclide are required as input parameters. These values are usually calculated by a burn-up code, such as ORIGEN or CORSOR. The entire progression from the initial event includes damage in the RPV and PCV and consequent leakage of water and steam.

After the accident, another code named "Severe Accident analysis code with Mechanistic, Parallelized Simulations Oriented towards Nuclear fields (SAMPSON)" [6], developed by Nuclear Power Engineering Corporation (NUPEC), has been improved by Institute of Applied Energy in Japan. The merit of the SAMPSON code is the fact that there is no factor adjusted by the user.

\subsubsection{Model 3: Atmospheric Transport Model}

Behavior of the radioactive materials released from a nuclear facility differs depending on their chemical properties, weather conditions (e.g., wind direction, wind speed, rainfall, snowfall), and the geography around the plant. Noble gases 
such as $\mathrm{Kr}$ or $\mathrm{Xe}$ are transported and dispersed by wind. If upward wind is predominant, the gases will be transported to the stratosphere and delivered across the entire earth by the wind. Gases of volatile radioactive materials such as $\mathrm{I}_{2}$ are also transported by the wind. CsI or Cs oxides can be transported by the wind if these nuclides float in the air as dust particles or attach to aerosols. This is called the "plume" as schematically shown in Fig. 3.2.

If rain or snow falls, some particles will fall to the surface of the earth together with raindrops (wash-out or rain-out) and contaminate the land. Therefore, prediction of the transport of radionuclides, i.e., evolution of the plume, is crucial for protecting local residents from radiation. Note, in contrast, that relatively large particles such as fuel grains are rather difficult to be transported far by the wind, so they tend to fall out by gravity near the NPS.

The time-integrated concentration of the released nuclides in the atmosphere, $\chi(x, y, z)\left[\mathrm{Bq} / \mathrm{m}^{3}\right]$, can be formulated by the Gaussian model as:

$$
\chi(x, y, z)=\frac{\Gamma}{2 \pi U \sigma_{y} \sigma_{z}} \exp \left(-\frac{y^{2}}{2 \sigma_{y}^{2}}\right)\left\{\exp \left(-\frac{(z-h)^{2}}{2 \sigma_{z}^{2}}\right)+\exp \left(-\frac{(z+h)^{2}}{2 \sigma_{z}^{2}}\right)\right\}
$$

where $\Gamma$ is the release rate at source $[\mathrm{Bq} / \mathrm{s}], U$ the mean wind speed in the $x$ direction $[\mathrm{m} / \mathrm{s}], h$ the physical height where the plume comes out [7]. The diffusion parameters, $\sigma_{\mathrm{y}}$ and $\sigma_{\mathrm{z}}$, represent the broadening in the transverse and vertical direction, respectively. Their values can be found in the data chart known as the Pasquill-Gifford diagram shown in Fig. 3.5, which categorizes air-stability into 6 classes, A-F, depending on local solar radiation and surface wind speed [7]. One can see from this figure that the lateral spread of the plume is only $1 / 10-1 / 100$ the

(a)

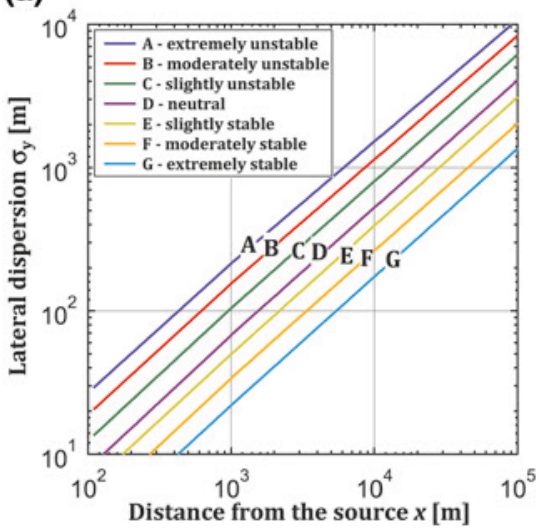

(b)

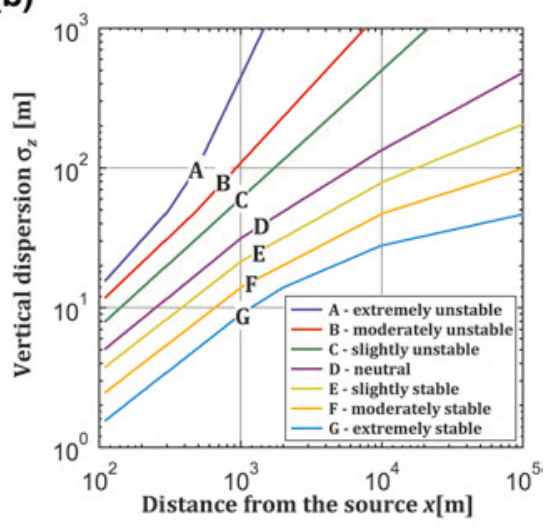

Fig. 3.5 Pasquill-Gifford dispersion diagrams: a horizontal dispersion, ground sources; $\mathbf{b}$ vertical dispersion, ground sources. In Japan, an extremely stable class $\mathrm{G}$ is added to classes A-F (see Appendix A of this chapter) 
travel distance necessary to deliver local effects to the environment. Nevertheless, the atmospheric diffusions are larger than that deduced from molecular collisional diffusion, since the turbulent flows enhance the net diffusion.

Because Eq. (3.2) is only applicable to the simple condition, i.e., flat topography and temporally and spatially constant wind, it is not suitable for the real-time simulation of atmospheric dispersion of radionuclides during emergency. Thus, more sophisticated model is used for this purpose. The System for Prediction of Environmental Emergency Dose Information (SPEEDI) [8] predicts the atmospheric dispersion and deposition of released radionuclides in the local and regional areas by solving the transport and diffusion equation numerically in which threedimensional meteorological fields and topography are considered explicitly. A worldwide version of SPEEDI (WSPEEDI) [9] can predict in detail the process of the atmospheric dispersion and deposition of released radioactive materials over the world for overseas accident.

The behavior of radioactive materials released to the ocean is evaluated from transportation and dispersion along the ocean current, dispersion by the tidal stream and wind, precipitation to the bottom of the sea, and intake by fishes and their migration. The compartment model is used for evaluation of the contamination in the ocean. The amount of release directly to the ocean as contaminated water is not included in the assessment of the accident scale.

\subsubsection{Model 4: Ambient Dose Rate from the Contaminated Ground}

The total release of the radioactive material, that is the integral of the source term with respect to the period of release, can be roughly evaluated from the ground contamination caused by the fallout/rainout/washout after the radiation plume has passed through, based on the following equations.

$$
\begin{gathered}
D_{j}\left(t_{o b s}\right)=\left[A_{j}^{\prime}\left(t_{c o m}\right)\right]\left(\frac{1}{2}\right)^{\left(t_{o b s}-t_{c o m}\right) / \tau_{j}} C F_{g r d, j} \\
\hat{D}_{j}\left(t_{o b s}\right)=D_{j}\left(t_{o b s}\right) / \sum_{j} D_{j}\left(t_{o b s}\right) \\
A_{j}\left(t_{s}\right)=\hat{D}_{j}\left(t_{o b s}\right)\left(\frac{1}{2}\right)^{\left(t_{s}-t_{o b s}\right) / \tau_{j}} C F_{g r d, j}^{-1} \cdot S F^{-1} \\
s_{i}=A_{j}\left(t_{s}\right) \frac{\text { Land }+ \text { ocean }}{\text { Land }}
\end{gathered}
$$

where $D$ and $A$ represent the dose rate $[\mathrm{Sv} / \mathrm{h}]$ and the radio activity of the surface area $\left[\mathrm{Bq} / \mathrm{m}^{2}\right]$, respectively. 
Fig. 3.6 Schematic drawing of evaluation of dose rate based on the ground shine

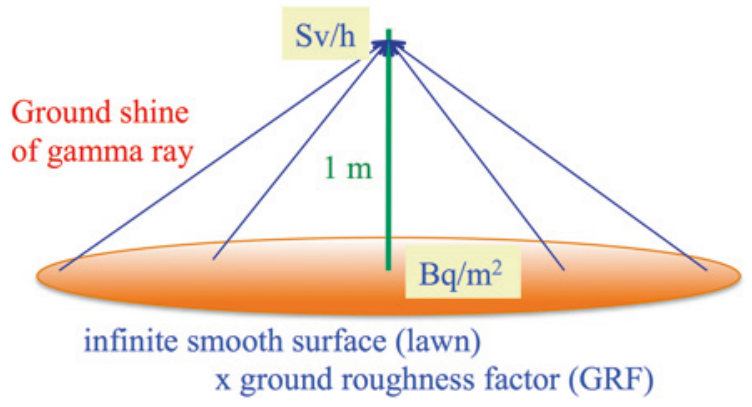

$C F_{\text {grd }}$ is the conversion factor from ground contamination to the ambient dose rate at $1 \mathrm{~m}$ above the ground, $\left[(\mathrm{Sv} / \mathrm{h}) /\left(\mathrm{Bq} / \mathrm{m}^{2}\right)\right]$ shown in Fig. 3.6, while $S F$ is the shielding factor depending on the ground condition, location, or buildings. We determined that $S F=0.7$ is a plausible value to be applied in the present situation (see Appendix C). $\tau$ is the half life of the radioactivity. $t_{\mathrm{com}}, t_{\mathrm{obs}}$ and $t_{\mathrm{s}}$ are the times when the species ratio is determined, when the dose rate was measured, and when the radioactive species are released, respectively. Note that the subscript $j$ is the label of the species and ${ }^{131} \mathrm{I}(\tau=8.02 \mathrm{~d}),{ }^{134} \mathrm{Cs}(\tau=752.4 \mathrm{~d})$, and ${ }^{137} \mathrm{Cs}$ $(\tau=11019.3 \mathrm{~d})$ in the present case.

\subsection{Occurrence of the Accident and Release, Transport, and Washout of the Radiation Plume}

From the severe-accident analysis based on the MAAP or MELCOR code, it is reported that the core damage incident for each unit happened approximately at the period listed in Table 3.1 .

Figure 3.7 shows the temporal evolution of the ambient dose rate observed inside the $1 \mathrm{~F}$ site, in nearby and distant cities, together with the wind conditions

Table 3.1 Core damage progression simulated by MAAP and MELCOR codes

\begin{tabular}{l|l|l|l|l}
\hline Simulation analysis & Unit & $1 \mathrm{~F} 1$ & $1 \mathrm{~F} 2$ & $1 \mathrm{~F} 3$ \\
\hline \multirow{3}{*}{ MAAP code (TEPCO) } & Core exposure & $3 \mathrm{~h}$ & $75 \mathrm{~h}$ & $40 \mathrm{~h}$ \\
\cline { 2 - 5 } & Core damage & $4 \mathrm{~h}$ & $77 \mathrm{~h}$ & $42 \mathrm{~h}$ \\
\cline { 2 - 5 } & RPV melt-through & $15 \mathrm{~h}$ & $109 \mathrm{~h}$ & $66 \mathrm{~h}$ \\
\hline \multirow{4}{*}{ MELCOR code (NISA) } & Core exposure & $2 \mathrm{~h}$ & $75 \mathrm{~h}$ & $41 \mathrm{~h}$ \\
\cline { 2 - 5 } & Core damage & $3 \mathrm{~h}$ & $77 \mathrm{~h}$ & $44 \mathrm{~h}$ \\
\cline { 2 - 5 } & RPV melt-through & $5 \mathrm{~h}$ & $80 \mathrm{~h}$ & $79 \mathrm{~h}$ \\
\hline \multirow{2}{*}{ Actual events } & IC/RCIC stopped & $2 \mathrm{~h} 50$ & $70 \mathrm{~h} \mathrm{39}$ & $35 \mathrm{~h} \mathrm{56}$ \\
\cline { 2 - 5 } & Vent (AO valve) & $23 \mathrm{~h} 44$ & Failed? & $42 \mathrm{~h} \mathrm{30}$ \\
\cline { 2 - 5 } & Explosion/rupture & $24 \mathrm{~h} 50$ & $77 \mathrm{~h}$ & $68 \mathrm{~h} 12$ \\
\hline
\end{tabular}

Hours from scram (March 11, 2011, 14:46 JST) 


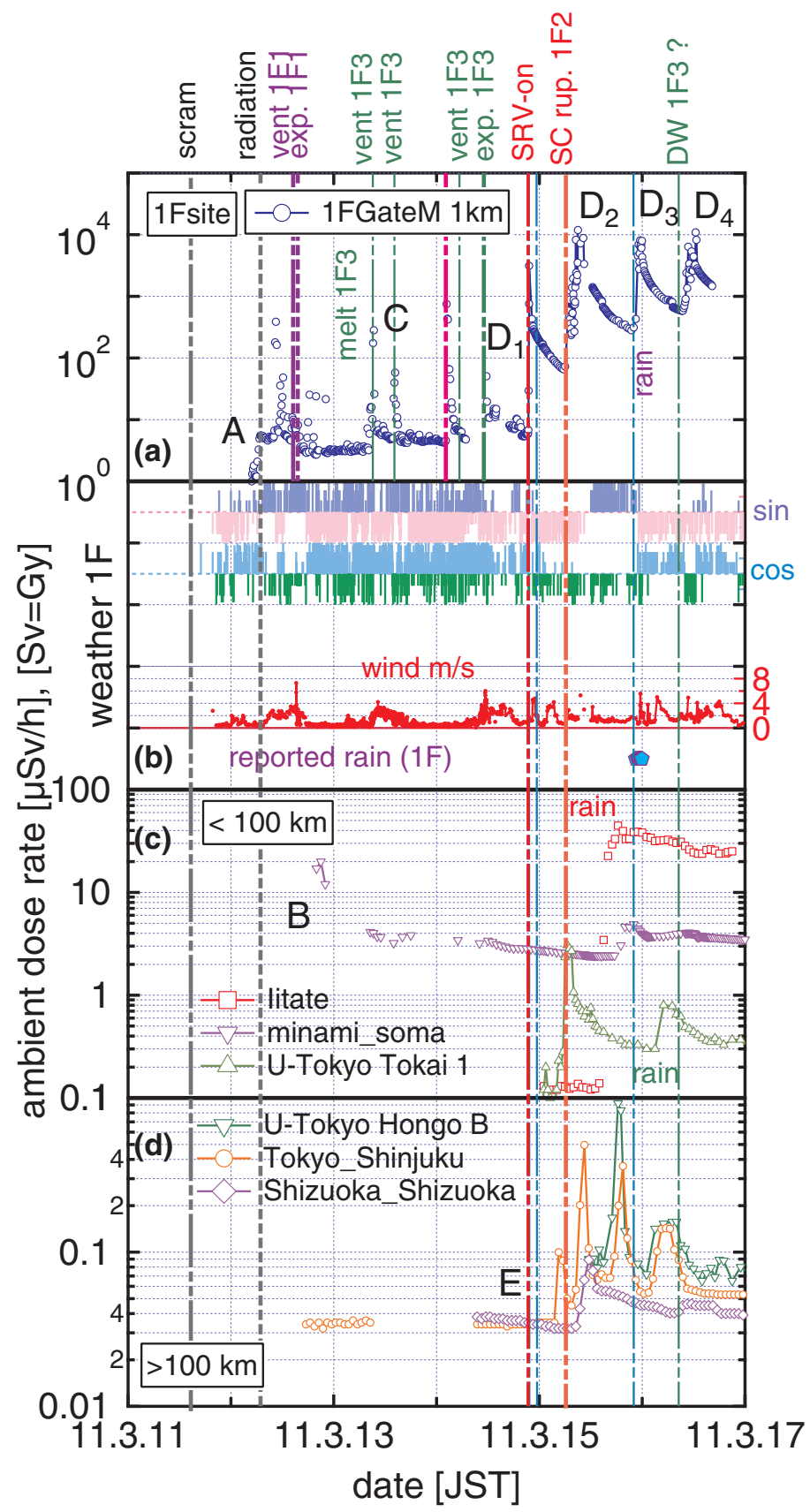

Fig. 3.7 Temporal evolution of the ambient dose rate at a $1 \mathrm{~F}$ monitoring post, $\mathbf{c}$ nearby, and d distant, b wind direction indicated by sine and cosine components (data from the University Tokyo and those publicly released by TEPCO and MEXT) 
at the $1 \mathrm{~F}$ monitoring posts (MPs). Note that in $1 \mathrm{~F}$, a monitoring car was used because the MPs were not working due to the power failure. The direction and speed of the wind were recorded with a 16 point compass, e.g. north $(\mathrm{N})$, northnorthwest (NNW), northwest (NW), west-northwest (WNW), south (S), east (E), etc., at the same time as the radiation dose rate at the monitoring posts/car in $1 \mathrm{~F}$. In order to compare the temporal evolution of the wind vector with other events, we represented the wind direction $\theta$ as the sine and cosine components of the direction (orienting to the east being $0^{\circ}$, while orienting to the north being $90^{\circ}$ ). In the present analysis, $\sin (\theta)>0$ corresponds to the direction from the land to the ocean, while $\cos (\theta)<0$ corresponds to the direction to the south (toward Tokyo).

At the $1 \mathrm{~F}$ site, the dose rate began to increase from 4:04 on March 12 (13 h after scram), which presumably coincides with the incidents in $1 \mathrm{~F} 1$ (Fig. 3.7, A). First, venting and the following hydrogen explosion was presumed to be the cause of the increase in the dose rate in Minami-sōma, $26 \mathrm{~km}$ north of 1F, on March 12 (Fig. 3.7, B). Note, however, that precise data recorded every $20 \mathrm{~s}$ (telemeter system) disclosed in November 2013 revealed that the rapid increase of dose rate at Kamihatori $6 \mathrm{~km}$ north west of $1 \mathrm{~F}$ coincided with the attempt to vent around 14:30 while the hydrogen explosion at 15:36 did not cause apparent increase in the dose rate around $1 \mathrm{~F}$.

The core damage incident in 1F3 occurred on March 13. The venting of the PCV of 1F3 was operated several times in the depressurizing procedure of the RPV during March 13 and 14, and the hydrogen explosion occurred at 11:01 on March 14 ( $68 \mathrm{~h}$ after scram). The fact that the wind was directed to the east (sea direction) during this period was, so to say, one consolation in the disaster (Fig. 3.7, C). However, the release of the radioactive materials in this event was considerably smaller than the following incident in $1 \mathrm{~F} 2$.

The incident at 1F2 caused the most serious release of radioactive nuclides. The suspected leakage of the PCV caused the release of radioactive gases around 21:30 on March 14 (Fig. 3.7, $D_{1}$ ), which was several hours before detection of the sound of the explosion or rupture at the suppression chamber (SC) of 1F2 (at 6:10) (Fig. 3.7, $\mathrm{D}_{2}$ ). Note that for that time, we have not enough evidence to tell whether the event was an explosion or a rupture. On October 2, 2011, it was reported that the accident investigation commission of Tokyo Electric Power Company (TEPCO) determined from the signals recorded on a quake meter that the hydrogen explosion might not have occurred in 1F2. It is more likely that the sound was delivered from the hydrogen explosion at $1 \mathrm{~F} 4$, presumably caused by the escaped hydrogen from 1F3 through a duct.

The radioactive leakage from $1 \mathrm{~F} 2$ in this period (Fig. 3.7, $\mathrm{D}_{1}$ ), presumably caused by opening the safety relief valves (SRVs) followed by the leakage through the damaged PCV, initiated the radiation plume toward the South direction, and the increase in ambient dose was observed as the plume propagated and passed through the locations at a speed of about $10 \mathrm{~km} / \mathrm{h}$ (Fig. 3.7, E). The radiation plume was observed even in Tokyo (SW $230 \mathrm{~km}$ of 1F) and Shizuoka (SW $360 \mathrm{~km})$. 
Note that by using SRVs to depressurize the RPV, external water injection becomes possible. However, flash boiling (see Appendix B) can accelerate the core exposure. SRV operation after core damage can therefore cause a significant transport of radioactive materials out of the RPV into the SC.

Figure 3.8 shows the temporal evolution of the ambient dose observed at different locations after the initial prominent radioactive release on March 15.

\section{[North $<\mathbf{5 0} \mathbf{~ k m}$ from $\mathbf{1 F}$ ]}

The plume on March 15 (Fig. 3.7, $\mathrm{D}_{1}$ ) soon passed and the ambient dose rate decreased rapidly, particularly in distant locations. However, the plume initiated by the SC rupture (Fig. 3.7, $\mathrm{D}_{2}$ ), propagated to the Northwest direction and caused fallout/washout/rainout due to rainfall and/or snowfall. This contributed to the significant increase in dose rates in these areas, such as Iitate-mura (NW $40 \mathrm{~km}$ ) (Fig. 3.8, F).

Although the origin of the later peaks at the main gate (Gate $\mathrm{M}$ ) of $1 \mathrm{~F}$, indicated in Fig. 3.7 as $\mathrm{D}_{3}$ and $\mathrm{D}_{4}$, has not yet been rigorously identified, the release of radioactive materials still continued even after March 16. As a result, rainfall over a wide area to the south washed out the plume into the soil, leading to a significant increase in the ambient dose rate. This time the decrease in the dose rate was dominated by the radiation decay of the radioactive nuclides. On March 18 and 19, the wind blew toward the North direction, and several dose rate peaks were observed in Minami-sōma (N $30 \mathrm{~km}$ ). However, presumably because there was no rainfall, these plumes did not deposit material onto the ground (Fig. 3.8, G).

On March 21, although rain fell in Fukushima, the plume did not deposit material onto Minami-sōma, because the wind was heading south (Fig. 3.8, H).

This suggests that ground contamination occurred due to both the plume and rainfall.

\section{[South 50-100 km from 1F]}

Ibaraki prefecture, located south of Fukushima, was subjected to a considerable degree of washout/rainout on March 16 and 20, that can be seen from the increase of the baseline of the ambient dose rate, having a decay timescale of ${ }^{131} \mathrm{I}, 8.02 \mathrm{~d}$ (Fig. 3.8, I).

Just after the delivery of the plume, the decay of the short-lifetime radioactive nucleus was also observed, such as ${ }^{135} \mathrm{I}(6.7 \mathrm{~h})$, or ${ }^{132} \mathrm{I}$ in radiative equilibrium with ${ }^{132} \mathrm{Te}(78 \mathrm{~h})$ (Fig. 3.8, J).

\section{[South $>100 \mathbf{~ k m}$ from 1F]}

In Tokyo, rain on March 21 washed out the plume and increased the radiation dose rate, which led to a minor panic when ${ }^{131} \mathrm{I}$ was detected from the tap water source (Fig. 3.8, K).

In Shizuoka, at $360 \mathrm{~km}$ from 1F, one can see from the time difference between the rain and the increase in the dose rate that the plume arrived during rainy weather (Fig. 3.8, L).

This suggests that the plume remains no longer than a few days when new plumes are not delivered.

This speculation agrees with the observation of the radioactive material level of fallout in Tokyo per day [10]. Usually the fallout lasted around 3-4 days in 


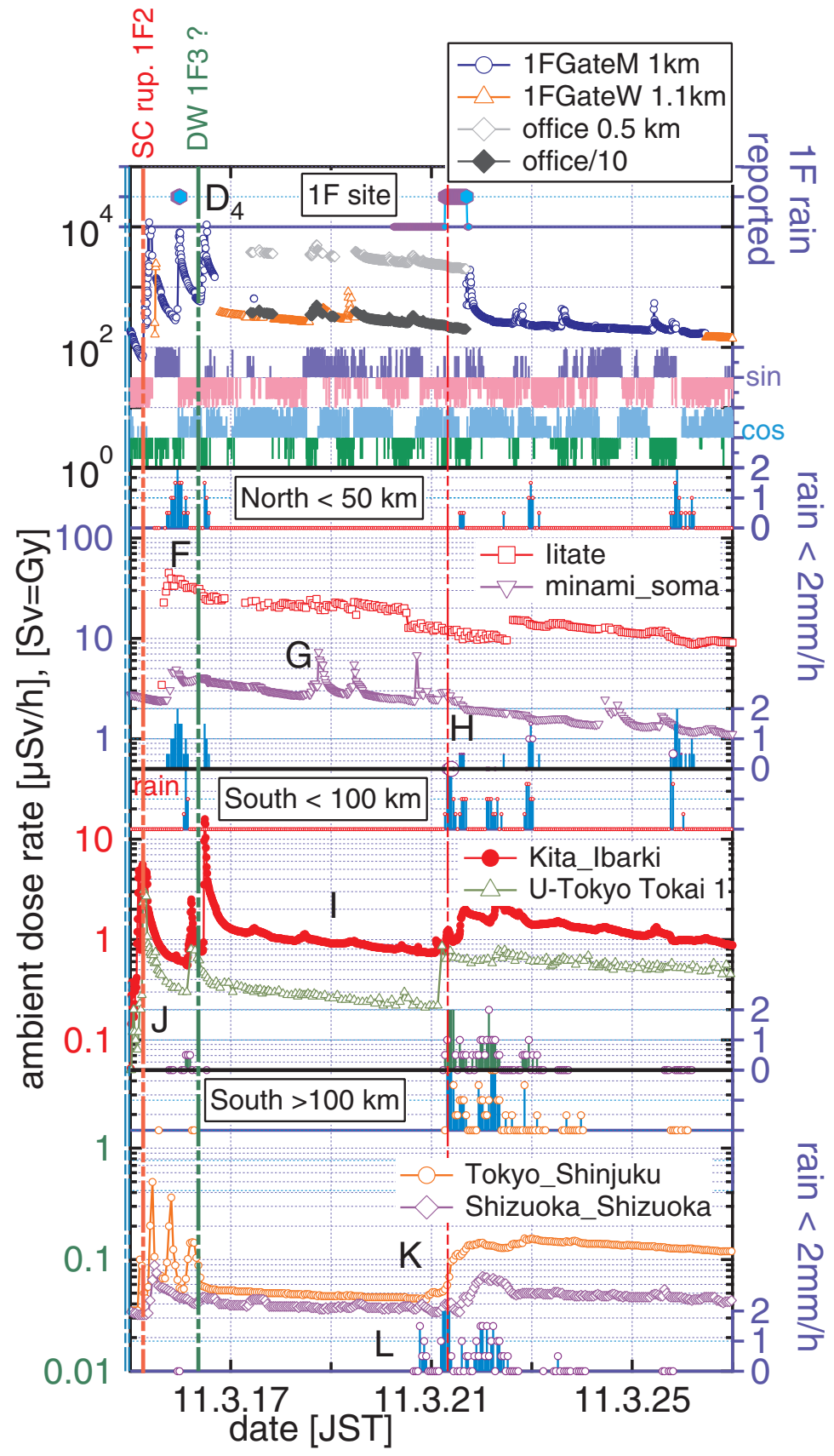

Fig. 3.8 Temporal evolution of the ambient dose rate of distant locations. Right axis corresponds to rain. Note Data for office $0.5 \mathrm{~km}$ from $1 \mathrm{~F}$ divided by 10 to scale its temporal behavior consistent with that of main gate (GateM) and west gate (GateW) 
March and April. For the purpose of protection from the radioactive exposure, it is preferable to watch the dose rate near one's location and the rain for a few days after passage of the plume. In particular, the rain causes cesium deposition onto soils, while removal of the deposited cesium is difficult. Therefore, we think that covering playgrounds with plastic sheets before it rains might be effective as an emergency protection against ground contamination-even a mattress or blanket is better than nothing. Some prefectural offices and nuclear power plants provide real-time dose rates. It might be preferable if one could watch these data together with rain and wind speed given in weather forecasts. At the same time, it might be required that not only the government but also scientists provide appropriate information about how to interpret the monitored data.

\subsection{Evaluations}

\subsubsection{Approach Based on Radionuclide Release Analysis: Model 1}

The behavior of released radioactive nuclides is complicated because it is closely related to the evolution of the accident. However, we made a rough evaluation, assuming that a certain proportion was released from the inventory in the fuel existing one day after the scram.

Figure 3.9 is an illustrative image of the behavior of radioactive materials in the reactor and their release to the environment. Release to the environment is basically composed of two steps: release from fuel (A) and release to the environment after release from the fuel (B). The latter release mechanism is complicated because detailed information of reactor damage and RI behavior in the damaged reactor is not simple. Radionuclides exist in various chemical forms in the RPV, PCV, and reactor building, such as gas, dissolved in water, aerosol, and

Fig. 3.9 Release fraction of leakage from reactor

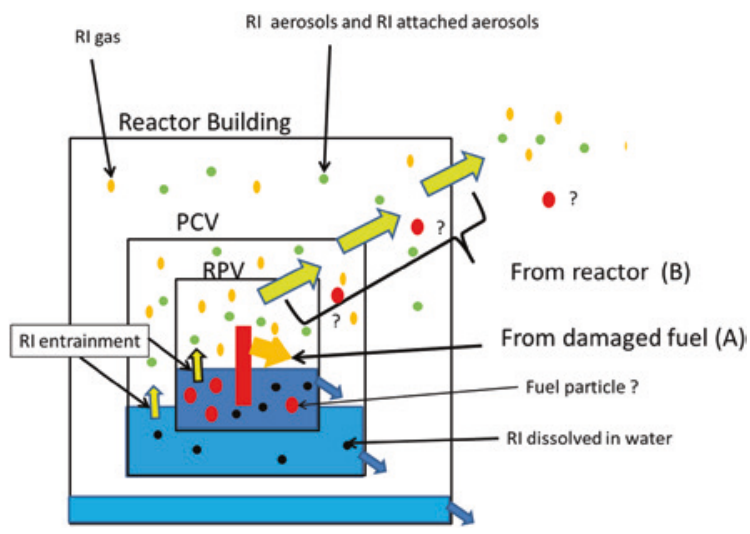




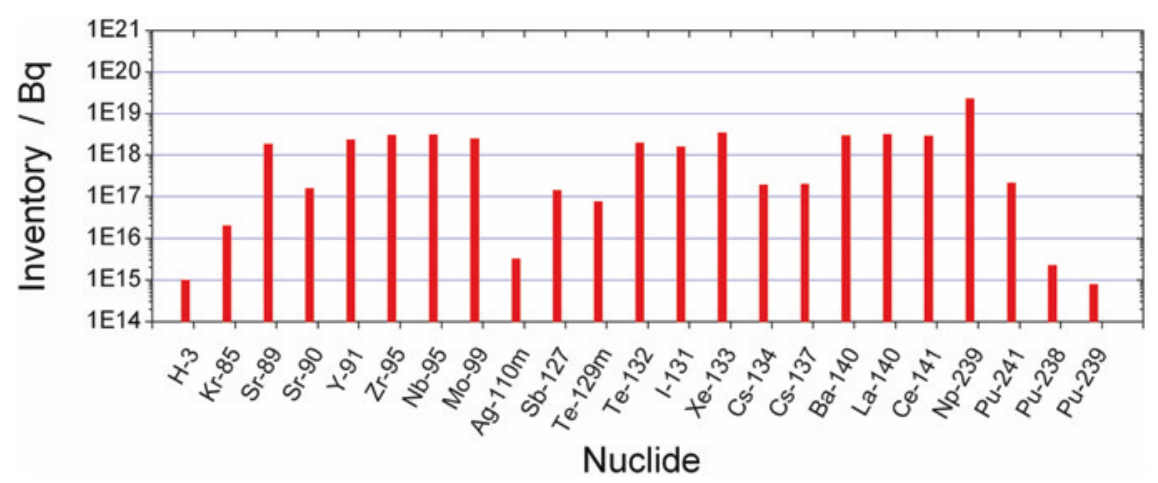

Fig. 3.10 The inventories of radionuclide at $1 F 1$ at one day after scram

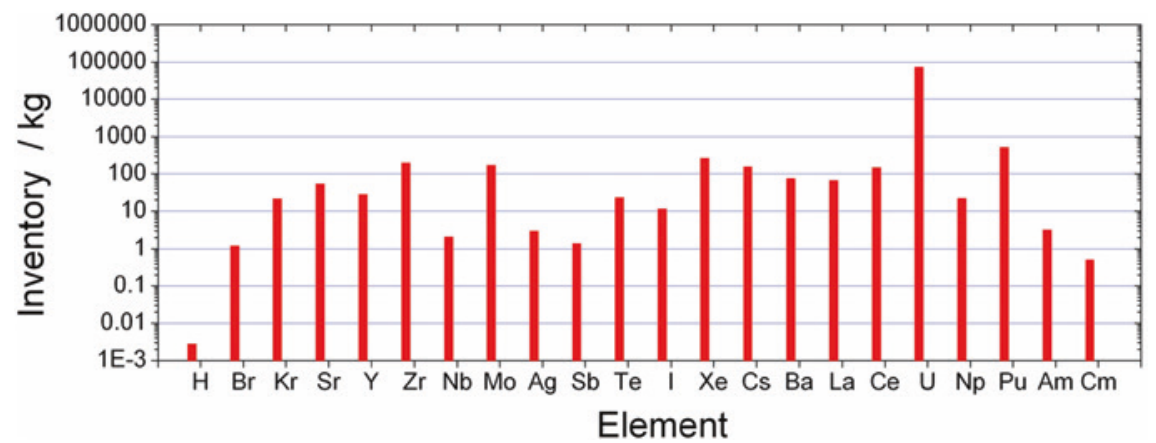

Fig. 3.11 Inventories of chemical elements in $1 \mathrm{~F} 1$ at one day after scram

solid particle. Entrainment of the species to the gas phase is also important in the dynamic or boiling state.

The electric power output, the number of fuel assemblies, and the average burnup at the scram of 1F1, 1F2, and 1F3 are (460 MWe, 400, $26 \mathrm{GWd} / \mathrm{t}),(784 \mathrm{MWe}$, 548, $23 \mathrm{GWd} / \mathrm{t}$ ), and (784 MWe, 548, $22 \mathrm{GWd} / \mathrm{t}$ ), respectively. Using these data, amounts of radionuclides and chemical elements for FP and MA at one day after the scram were calculated using the ORIGEN code. ${ }^{2}$ Figures 3.10 and 3.11 show the inventories of radionuclide and chemical elements in $1 \mathrm{~F} 1$ at one day after the scram, respectively.

Inventories in 1F2 and 1F3 at one day after the scram are about 1.5 times those for $1 \mathrm{~F} 1$. The following nuclides were found to be significant based on the produced amount and half-life: ${ }^{239} \mathrm{~Np}(2.36 \mathrm{~d}),{ }^{133} \mathrm{Xe}(5.25 \mathrm{~d}),{ }^{140} \mathrm{La}(1.68 \mathrm{~d}),{ }^{141} \mathrm{Ce}$

\footnotetext{
2 We made a rough estimate of inventory data on July 2011 with use of ORIGEN 2.2, assuming conditions about core and operation of the reactor, which might be considered similar to those of $1 \mathrm{~F} 1$.
} 
(32.51 d), ${ }^{131} \mathrm{I}(8.04 \mathrm{~d}),{ }^{137} \mathrm{Cs}(30.17 \mathrm{y}),{ }^{134} \mathrm{Cs}(2.06 \mathrm{y}),{ }^{89} \mathrm{Sr}(50.5 \mathrm{~d}),{ }^{90} \mathrm{Sr}(28.8 \mathrm{y})$, ${ }^{132} \mathrm{Te}(3.20 \mathrm{~d}),{ }^{129 \mathrm{~m}} \mathrm{Te}(33.6 \mathrm{~d}),{ }^{238} \mathrm{Pu}(87.7 \mathrm{y}),{ }^{239} \mathrm{Pu}(24,000 \mathrm{y}),{ }^{241} \mathrm{Pu}(14.4 \mathrm{y})$, ${ }^{140} \mathrm{Ba}(12.75 \mathrm{~d}),{ }^{95} \mathrm{Zr}(64.03 \mathrm{~d}),{ }^{91} \mathrm{Y}(58.51 \mathrm{~d}),{ }^{127} \mathrm{Sb}(3.85 \mathrm{~d}),{ }^{99} \mathrm{Mo}(65.94 \mathrm{~h}),{ }^{3} \mathrm{H}$ $(12.3 \mathrm{y})$, and ${ }^{85} \mathrm{Kr}(10.7 \mathrm{y})$. The chemical inventory shown in Fig. 3.11 gives us important information. For example the inventory of Cs is about ten times larger than that of I.

The chemical state can typically be categorized into noble gases $(\mathrm{Kr}, \mathrm{Xe})$, volatile materials (I, Cs, Te, H), and low volatile materials ( $\mathrm{Sr}, \mathrm{Y}, \mathrm{Pu}$ ). The degree of volatilization is a key to understanding the release during the accident.

The chemical forms and the location of radioactive materials released from the fuel depend on their chemical properties. Noble gases such as $\mathrm{Kr}$ and $\mathrm{Xe}$ exist in the gas phase and were released to the atmosphere by the venting operation. Iodine was released as CsI and dissolved in water. However, some chemicals exist in the gas phase as I attached to aerosol, $\mathrm{I}_{2}$, and organic iodine. Cs takes the chemical forms of $\mathrm{CsOH}$ and oxide as well as $\mathrm{CsI}$ in the gas phases or in water. Te exists as oxide in the gas phase or is dissolved in water. $\mathrm{Sr}$ is dissolved in water as a cation or exists as oxide in the gas phase or in water. Therefore, aerosols in the gas phase might carry these kinds of species.

In order to evaluate the radionuclide release from the fuel, we assumed the two cases of the temperature and the duration time as (i) $2,800{ }^{\circ} \mathrm{C}$ and $1 \mathrm{~h}$, and (ii) $2,000{ }^{\circ} \mathrm{C}$ and $4 \mathrm{~h}$. We used source terms based on the inventory at $1 \mathrm{~h}$ after scram for $1 \mathrm{~F} 1,1 \mathrm{~F} 2$, and $1 \mathrm{~F} 3$ for simplicity. The fraction of inventory released from the fuel is calculated by the release rate constants as shown for these two cases in Table 3.2. As can be seen from the comparison, all noble gases and volatile materials were released in both cases. However, the difference in the fraction is remarkable for $\mathrm{Ba}, \mathrm{Sr}, \mathrm{La}$, and $\mathrm{Pu}$.

Table 3.2 The fraction of inventory released from the fuel

\begin{tabular}{l|l|l|l}
\hline $2,800{ }^{\circ} \mathrm{C} 1 \mathrm{~h}$ & & $2,000{ }^{\circ} \mathrm{C} 4 \mathrm{~h}$ & \\
\hline $\mathrm{Xe}, \mathrm{Kr}$ & $100(\%)$ & $\mathrm{Xe}, \mathrm{Kr}$ & $100(\%)$ \\
\hline $\mathrm{H}$ & 100 & $\mathrm{H}$ & 100 \\
\hline $\mathrm{Cs}$ & 100 & $\mathrm{Cs}$ & 100 \\
\hline $\mathrm{I}$ & 100 & $\mathrm{I}$ & 100 \\
\hline $\mathrm{Te}$ & 100 & $\mathrm{Te}$ & 100 \\
\hline $\mathrm{Ba}$ & 83 & $\mathrm{Ba}$ & 29 \\
\hline $\mathrm{Sr}$ & 58 & $\mathrm{Sr}$ & 16 \\
\hline $\mathrm{Zr}$ & 1.7 & $\mathrm{Zr}$ & 0.34 \\
\hline $\mathrm{Np}$ & 1 & $\mathrm{~Np}$ & 0.5 \\
\hline $\mathrm{Mo}$ & 100 & $\mathrm{Mo}$ & 99 \\
\hline $\mathrm{La}$ & 1.7 & $\mathrm{La}$ & 0.34 \\
\hline $\mathrm{Pu}$ & 0.17 & $\mathrm{Pu}$ & 0.034 \\
\hline $\mathrm{Am}$ & 1 & $\mathrm{Am}$ & 0.5 \\
\hline
\end{tabular}


Chemical properties such as the vapor pressure of each element must be taken into account in the release rate from RPV and PCV as shown in Fig. 3.9. Some appropriate assumptions must be made for estimates of released amounts by the accident, except for noble gases (fully released). Released radioactive materials exist in the water or steam of the RVP and PCV due to their chemical properties and damage to the RPV and PCV. Particles in the fuel generated by rapid cooling after melting might be dispersed in the water. Some parts of the radionuclide in the gas phase were released in the accident. Some part of the species in the liquid phase is considered to have been transported to the gas phase by the entrainment. The release fraction to the environment from the reactor is very complicated because it reflects various events causing RI release, such as seat leakage from the flanges or bulbs (including SRV release to a leaking vessel), venting, hydrogen explosion, and damage to the suppression chamber. Therefore, we tentatively assumed the release fraction [(B) in Fig. 3.9] from the RPV + PCV + Reactor Building to the atmosphere considering the vapor pressure of the elements: Xe $100 \%$; Kr 100\%; Cs $1 \%$; I $1 \%$; Te $0.1 \%$; Sr $10^{-4}$; Ba $10^{-4}$; Zr 10 $10^{-4}$; Np 10 ${ }^{-4}$; $\mathrm{Pu} 10^{-5} ;{ }^{3} \mathrm{H} 25 \%$; etc. In this evaluation we also assumed these releases occurred at one day after the scram by the earthquake. Although these assumptions are different from the actual accident scheme, our estimation can give us a fundamental understanding of RI release. ${ }^{3}$

We calculated released amounts to the environment by multiplying the inventory by the release fraction from the fuel [(A) in Fig. 3.9] and by that from the reactor [(B) in Fig. 3.9]. The calculation results of amounts released are: ${ }^{3} \mathrm{H}$ $9.4 \times 10^{14} \mathrm{~Bq} ;{ }^{85} \mathrm{Kr} 7.6 \times 10^{16} \mathrm{~Bq} ;{ }^{89} \mathrm{Sr} 3.9 \times 10^{14} \mathrm{~Bq} ;{ }^{90} \mathrm{Sr} 3.5 \times 10^{13} \mathrm{~Bq} ;{ }^{129} \mathrm{~m} \mathrm{Te}$ $2.9 \times 10^{14} \mathrm{~Bq} ;{ }^{131} \mathrm{I} 6.0 \times 10^{16} \mathrm{~Bq} ;{ }^{133} \mathrm{Xe} 1.3 \times 10^{19} \mathrm{~Bq} ;{ }^{137} \mathrm{Cs} 7.6 \times 10^{15} \mathrm{~Bq} ;{ }^{134} \mathrm{Cs}$ $7.4 \times 10^{15} \mathrm{~Bq} ;{ }^{249} \mathrm{~Np} 8.8 \times 10^{13} \mathrm{~Bq} ;{ }^{241} \mathrm{Pu} 1.4 \times 10^{10} \mathrm{~Bq} ;{ }^{241} \mathrm{Am} 8.9 \times 10^{7} \mathrm{~Bq}$ for fuel damage at $2,800{ }^{\circ} \mathrm{C}$ for $1 \mathrm{~h}$. The ${ }^{131} \mathrm{I}$ equivalent amount of radionuclide is evaluated as $4.9 \times 10^{17} \mathrm{~Bq}$ using the conversion factor in the INES manual (Table 3.3).

The Nuclear and Industrial Safety Agency (NISA) reported it as $7.7 \times 10^{17} \mathrm{~Bq}$ calculated by the MELCOR code [10].

As to the release points of radioactive materials, they are released from the venting stack in accidents without severe damage. However, in the $1 \mathrm{~F}$ accident, these were also released from the disrupted points of the PCV, duct pipes, and the reactor building. Moreover, contaminated water was released into the sea through the tunnel of $1 \mathrm{~F} 2$ from a crack in the concrete pit.

\footnotetext{
${ }^{3}$ Facts to provide evidence about what actually occurred are not fully confirmed. The facts and the radionuclide behavior will be made clear within the decommissioning. Therefore, we provide assumptions considering those chemical properties.
} 
Table 3.3 The multiplication factors based on the ${ }^{131} \mathrm{I}$ equivalence which are calculated by effective dose from external radiation and inhalation following the INES manual

\begin{tabular}{l|l}
\hline Radionuclide & Multiplication factor based on ${ }^{131} \mathrm{I}$ \\
\hline${ }^{3} \mathrm{H}$ & 0.02 \\
\hline${ }^{85} \mathrm{Kr}$ & 0.001 \\
\hline${ }^{89} \mathrm{Sr}$ & 0.50 \\
\hline${ }^{90} \mathrm{Sr}$ & 20 \\
\hline${ }^{106} \mathrm{Ru}$ & 6 \\
\hline${ }^{115} \mathrm{Ag}$ & 0.10 \\
\hline${ }^{125} \mathrm{Sb}$ & 0.07 \\
\hline${ }^{127} \mathrm{Sb}$ & 0.8 \\
\hline${ }^{129 \mathrm{~m}} \mathrm{Te}$ & 0.1 \\
\hline${ }^{132} \mathrm{Te}$ & 0.6 \\
\hline${ }^{131} \mathrm{I}$ & 0.3 \\
\hline${ }^{133} \mathrm{Xe}$ & 1 \\
\hline${ }^{134} \mathrm{Cs}$ & 0.008 \\
\hline${ }^{137} \mathrm{Cs}$ & $3\left({ }^{\mathrm{a}} 20\right)$ \\
\hline${ }^{140} \mathrm{Ba}$ & 40 \\
\hline${ }^{237} \mathrm{U}$ & 1 \\
\hline${ }^{239} \mathrm{~Np}$ & 0.1 \\
\hline${ }^{241} \mathrm{Pu}$ & 0.07 \\
\hline
\end{tabular}

${ }^{\text {a }}$ See in detail Appendix $\mathrm{C}$

\subsubsection{Approach Based on Radiation Monitor}

\subsubsection{Result of the Standard Method Based on SPEEDI Simulation: Model 3}

The Nuclear Safety Commission of Japan (NSC) reported the source term of ${ }^{131} \mathrm{I}$ and ${ }^{137} \mathrm{Cs}$ released between March 12 and April 5 based on atmospheric dispersion simulations, such as SPEEDI or WSPEEDI. The simulation result for the unit release rate $\left(1 \mathrm{~Bq} \mathrm{~h}^{-1}\right)$ was compared to that obtained by the dust-sampler to normalize the absolute value. They obtained: $150 \mathrm{PBq}$ for ${ }^{131} \mathrm{I}$, and $12 \mathrm{PBq}$ for ${ }^{137} \mathrm{Cs}$ $\left(1 \mathrm{PBq}=10^{15} \mathrm{~Bq}\right)$. In order to obtain the radiological equivalence to ${ }^{131} \mathrm{I}$ release, the value for ${ }^{137} \mathrm{Cs}$ was multiplied by 40 , yielding the total ${ }^{131} \mathrm{I}$ equivalent release of $630 \mathrm{PBq}[11,12]$. Minor corrections were made to these data to equal $570 \mathrm{PBq}$ $\left({ }^{131} \mathrm{I}: 130 \mathrm{PBq}\right.$ and ${ }^{137} \mathrm{Cs}$ : $\left.11 \mathrm{PBq}\right)$ on August 22 . Note that the reverse estimation based on the SPEEDI simulation has been further improved by including the radiation data.

However, the results of the SPEEDI calculation were only disclosed on March 23, and on April 11. The government finally admitted that more than 5,000 evaluation results had existed from the beginning of the accident, which had not been disclosed for fear of public panic. 
Because these evaluations rely on simulation codes and detailed weather data inaccessible to the public, we proposed a simple but straightforward estimation from the ambient dose rate data, or radiation map, available at many locations.

\subsubsection{Alternative Method Based on Ground Shine: Model 4}

The ratio of the radioactivity $A^{\prime}$ in Eq. (3.3) can be determined at the specific time when all species of interest can be commonly determined from measurements, such as dust sampling, soil analysis, or simulations.

We adopted the Becquerel ratio $\left[{ }^{131} \mathrm{I}\right]:\left[{ }^{134} \mathrm{Cs}\right]:\left[{ }^{137} \mathrm{Cs}\right]=1: 1: 1$ on $t_{\mathrm{com}}=$ April 10 from air sampling data at the Comprehensive Nuclear-Test-Ban Treaty (CTBT) National Operation System of Japan in Takasaki, Gunma prefecture [13].

In this case, taking $t_{\mathrm{obs}}=$ April 5 for instance, the normalized dose ratio can be calculated to be 0.21:0.57:0.22 from Eq. (3.3) followed by normalization using Eq. (3.4). This ratio agrees with the species-sensitive dose monitoring in Ichihara, Chiba prefecture, reported by Japan Chemical Analysis Center [14].

For Eq. (3.5), we corrected data from the dose rate, of locations categorized into the following groups.

(i) Inside $20 \mathrm{~km}$ no-go zone:

For inside the $20 \mathrm{~km}$ no-go zone, TEPCO monitored the dose rate during March 30-April 2 and April 18-19, the results of which are listed with the distance from 1F [15]. The data are shown in Fig. 3.12 as a function of the distance from the $1 \mathrm{~F}$ site. Although the scattering of the data showed significant directional dependence, the general trend exhibited the decaying property. Therefore, we performed an exponential decay fitting to determine the rough integral of the dose rate in this area based on the following equation,

$$
D_{j}(0) \int_{0}^{\infty} 4 \pi r \exp \left(-\frac{r}{L}\right) d r=4 \pi D_{j}(0) L^{2}
$$

Fig. 3.12 Dose rates at locations inside $20 \mathrm{~km}$ no-go zone, scaled to that on March 15 when dominant radioactive release occurred

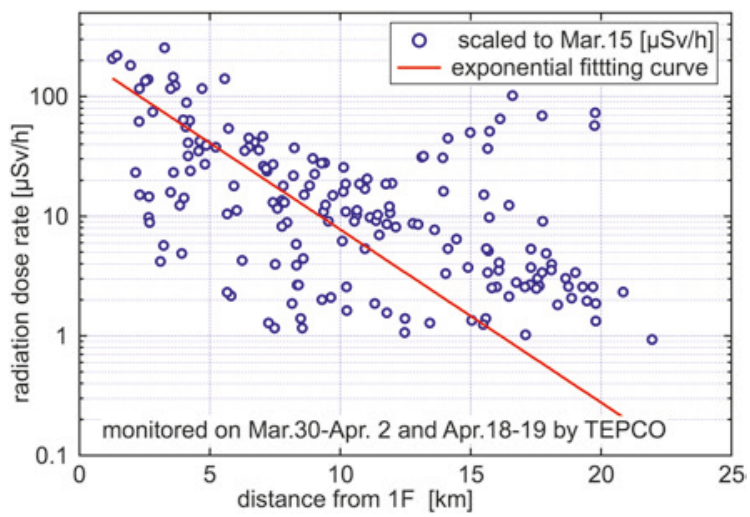


Fig. 3.13 Dose rate mapping of schools in Fukushima performed in April. Upper diagram is the projection along the latitude
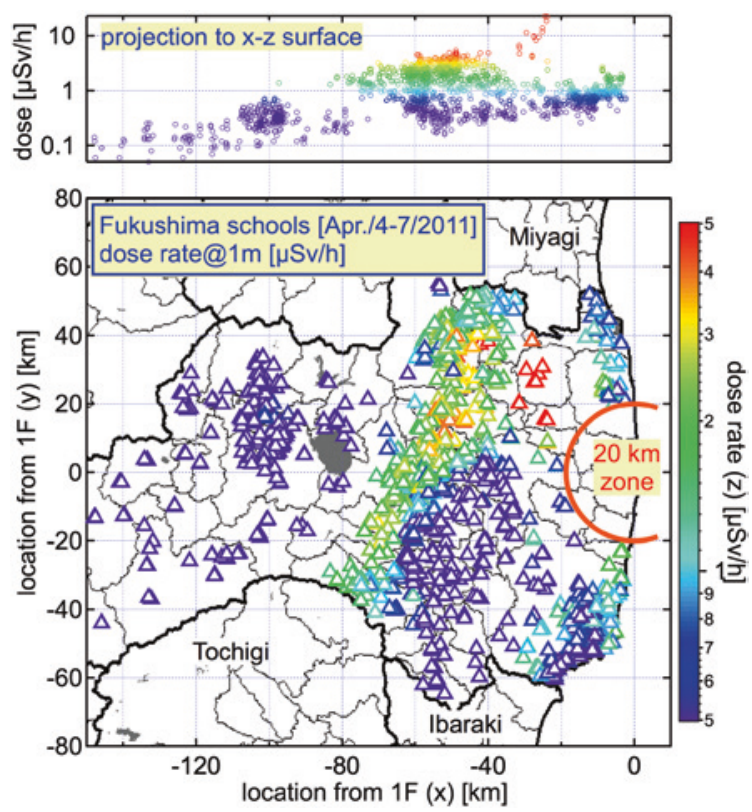

where, $L$ is the characteristic length of the spatial decay while $D_{j}(0)$ is the dose rate extrapolated to the origin, namely the $1 \mathrm{~F}$ plant.

(ii) East part of Fukushima prefecture outside the $20 \mathrm{~km}$ no-go zone, and (iii) West part of Fukushima prefecture:

The administrative authority of Fukushima prefecture conducted gamma dose rate monitoring at more than 1,600 schools all over Fukushima except inside the $20 \mathrm{~km}$ circle from 1F during April 4-7, 2011 [16]. In this period, the contribution of ${ }^{131}$ I to the dose rate was still obvious, so it can be used to evaluate the radioactive release. A dose rate map of these data is shown in Fig. $3.13^{4}$ together with the 1-dimensional distribution projected along the latitude direction.

It may safely be said that Fukushima Prefecture outside the $20 \mathrm{~km}$ no-go zone was divided into two parts, East (ii) and West (iii) areas, which are approximately equal in size. We distributed 1,370 points to (ii) and 267 points to (iii) depending on their location. As a result, one data point in (ii) and (iii) can be regarded as representing an area of around 4.57 and $28.6 \mathrm{~km}^{2}$, respectively [area of the half disk $20 \mathrm{~km}$ in radius was removed from the area of half of the prefecture in (ii)].

\section{(iv) Ibaraki prefecture:}

Ibaraki Prefecture, located south of Fukushima prefecture, exhibited a relatively higher dose rate among the adjacent prefectures. We assumed the excess dose

\footnotetext{
${ }^{4}$ Fukushima map from "National Land numerical information (Administrative Divisions, 2011), Ministry of Land, Infrastructure, Transport and Tourism, file: japan_ver71, processed by ESRI Japan”.
} 
rate of Mito City on April 10, $0.17 \mu \mathrm{Sv} / \mathrm{h}$, as representing the averaged values for Ibaraki prefecture.

(v) Tochigi, Chiba, Gunma prefectures, and others:

For a minor correction of the evaluation, the area of these three prefectures was regarded as representing ground contamination in distant places. The excess dose rate was assumed to be $0.07 \mu \mathrm{Sv} / \mathrm{h}$ on April 10 .

The largest ambiguity in evaluating the released radioactive materials is in the fraction of the ground deposition against the total release. Atmospheric simulations also have a considerable amount of error depending on the modeling.

We had first approximated the fraction at about half. Actually, Ref. [17] reported from the atmospheric dispersion model GEARN in WSPEEDI-II that these fractions for ${ }^{131} \mathrm{I}$ and ${ }^{137} \mathrm{Cs}$ are 0.44 and 0.46 , respectively-i.e., it can be suspected that the fraction for ${ }^{134} \mathrm{Cs}$ is also 0.46. However, Ref. [18] implies, from a three-dimensional chemical transport model, Models 3 Community Multiscale Air Quality (CMAQ), that the fractions for ${ }^{131} \mathrm{I},{ }^{134} \mathrm{Cs}$, and ${ }^{137} \mathrm{Cs}$ deposits on land were $0.13,0.22$, and 0.22 , respectively. We have updated the evaluation using these value ranges. The results are shown in Table 3.4. Smaller values are the result of adopting Ref. [17] as the fraction for the land deposition, while larger values are those adopting Ref. [18].

From these results, the ${ }^{131} \mathrm{I}$ equivalent released radioactive nucleus was evaluated to be 337-782 PBq.

The databases necessary to evaluate the ground contamination are compiled in Appendix C. Note that the ambiguity in ${ }^{137} \mathrm{Cs}$ has a large effect on the ${ }^{131}$ I equivalent value, since the multiplying factor is as large as 40 .

In this rough evaluation, different from that of NSC, we did not address the daily changes in the release rate, based on the assumption that almost all released species had been fallout/rainout/washout and the fraction of those on the land

Table 3.4 Evaluated ground contamination and source terms in $\mathrm{PBq}$

\begin{tabular}{|c|c|c|c|}
\hline & ${ }^{131} \mathrm{I}$ & ${ }^{134} \mathrm{Cs}$ & ${ }^{137} \mathrm{Cs}$ \\
\hline (i) & 8.03 & 0.95 & 0.93 \\
\hline (ii) & 12.5 & 1.47 & 1.44 \\
\hline (iii) & 2.33 & 0.27 & 0.27 \\
\hline (iv) & 1.35 & 0.16 & 0.16 \\
\hline (v) & 1.63 & 0.19 & 0.19 \\
\hline Total on land & 25.8 & 3.05 & 2.98 \\
\hline Land fraction & $0.13 / 0.44$ & $0.22 / 0.46$ & $0.22 / 0.46$ \\
\hline Source term & $199 / 59$ & $13.8 / 6.6$ & $13.6 / 6.5$ \\
\hline (factor) & (1) & (3) & $(40)$ \\
\hline I-eq. & $199 / 59$ & $41.6 / 20$ & $542 / 258$ \\
\hline$\left(\right.$ factor $\left.^{\mathrm{a}}\right)$ & (1) & $(20)^{\mathrm{a}}$ & (40) \\
\hline I-eq. ${ }^{\text {a }}$ & $199 / 59$ & $277 / 132$ & $542 / 258$ \\
\hline
\end{tabular}

${ }^{\mathrm{a}}$ Multiplication factor for ${ }^{131} \mathrm{I}$ equivalent for ${ }^{134} \mathrm{Cs}$ was corrected from 3 to 20 (see Appendix C) 
had contributed to the dose rate. Ambiguity in the fraction that was deposited on land also has a direct effect on the evaluation of the source terms. One needs to be reminded that this is also true for the other method based on atmospheric transport simulation.

\subsubsection{Crosscheck of the Evaluation}

The result in the previous subsection was compared to the June 14 cesium radiation map of Fukushima and adjacent prefectures and was presented by the Ministry of Education, Culture, Sports, Science and Technology (MEXT) on September 30. There were 1,732 data points located in Fukushima prefecture [19, 20].

By correcting the data to that on March 15, using Eq. (3.5), total ground contamination values scaled on March 15 of Fukushima prefecture of ${ }^{134} \mathrm{Cs}$ and ${ }^{137} \mathrm{Cs}$ are 2.5 and 2.6 PBq, yielding source terms of 32 and $470 \mathrm{PBq}$, respectively, which agree well with the sum of our evaluations (i), (ii), and (iii).

Fallout of ${ }^{131} \mathrm{I},{ }^{134} \mathrm{Cs}$, and ${ }^{137} \mathrm{Cs}$ has been monitored at specific cities in every prefecture in Japan except Fukushima and Miyagi [21]. We summed up the monthly fallout in $\mathrm{Bq} / \mathrm{m}^{2}$ in each prefecture multiplied by the area of each prefecture in $\mathrm{m}^{2}$, yielding $0.4 \mathrm{PBq}$ for ${ }^{137} \mathrm{Cs}$. This value roughly agrees with our evaluation for areas in (iv) and (v).

Moreover, we would like to emphasize that these different methods lead to results consistent with each other for source term, release rate, dust sampling, fallout, and dose rate by ground shine with $S F=0.7$ (see Appendix C for detail).

\subsubsection{Comparison Between Approaches}

Evaluation results based on these approaches are compared in Table 3.5. All of them exceeded the criteria of INES accident level $7\left(>10^{16} \mathrm{~Bq}\right)$. For comparison, results for the Chernobyl accident are also listed. These rough evaluations, calculations practically done by hand, were able to obtain approximated release amounts of radioactive materials.

It is worthwhile to mention that the total amounts of radionuclides of the Chernobyl accident were $1,800 \mathrm{PBq}$ for ${ }^{131} \mathrm{I}$, and $85 \mathrm{PBq}$ for ${ }^{137} \mathrm{Cs}$, yielding the radiological equivalence of ${ }^{131} \mathrm{I}$ of $5,200 \mathrm{PBq}$. This is considerably larger than that of the Fukushima Daiichi accident. The reason for this fact is not only because the PCV covers the RPV in the Fukushima case, but also because in the Chernobyl case, a massive amount of $\mathrm{Cs}, \mathrm{I}, \mathrm{Sr}$, and $\mathrm{Pu}$ was released to the environment by steam explosion of the melted fuel.

The accident level assessment based on INES (see Appendix C) has been performed by the radiological equivalence to ${ }^{131} \mathrm{I}$ for ${ }^{131} \mathrm{I}$ and ${ }^{137} \mathrm{Cs}$ release. The release of ${ }^{134} \mathrm{Cs}$ has not been included. Indeed, the effect of ${ }^{134} \mathrm{Cs}$ is small if one 
Table 3.5 Comparison between different approaches to evaluate the total release in $\mathrm{PBq}$

\begin{tabular}{|c|c|c|c|c|c|c|}
\hline & \multirow[t]{2}{*}{ Method } & \multirow{2}{*}{$\begin{array}{l}{ }^{131} \mathrm{I} \\
\text { equivalent }\end{array}$} & ${ }^{131} \mathrm{I}$ & ${ }^{134} \mathrm{Cs}$ & ${ }^{137} \mathrm{Cs}$ \\
\hline & & & & $\mathrm{x} 1$ & x 3 & $\mathrm{x} 40$ \\
\hline \multirow[t]{2}{*}{$\begin{array}{l}\text { Radionuclide } \\
\text { release } \\
\text { analysis }\end{array}$} & $\begin{array}{l}\text { Model } 1 \\
\text { (this study) }\end{array}$ & $\begin{array}{l}\text { ORIGEN } \\
\text { CORSOR-O } \\
\text { chemical analysis }\end{array}$ & 490 & 60 & 7.4 & 7.6 \\
\hline & $\begin{array}{l}\text { Model } 2 \text { by } \\
\text { NISA }\end{array}$ & MAAP/MELCOR & $370(770)$ & $\begin{array}{l}130 \\
(160)\end{array}$ & - & $6.1(15)$ \\
\hline \multirow[t]{2}{*}{$\begin{array}{l}\text { Radiation } \\
\text { monitor }\end{array}$} & $\begin{array}{l}\text { Model } 3 \text { by } \\
\text { NSC }\end{array}$ & $\begin{array}{l}\text { SPEEDI dust } \\
\text { sampling }\end{array}$ & $630(570)$ & $\begin{array}{l}150 \\
(130)\end{array}$ & - & $12(11)$ \\
\hline & $\begin{array}{l}\text { Model } 4 \\
\text { (this study) }\end{array}$ & $\begin{array}{l}\text { Radiation map } \\
\text { (ground shine) }\end{array}$ & $337-782$ & $59-199$ & $6.6-13.8$ & $6.5-13.6$ \\
\hline Chernobyl & & $\begin{array}{l}\text { Core inventory } \\
\text { analysis code }\end{array}$ & 5,200 & 1,800 & - & 85 \\
\hline
\end{tabular}

Some data have been updated from the initial publication, indicated in parentheses. We kept ${ }^{131}{ }^{I}$ equivalent multiplication factor for ${ }^{134} \mathrm{Cs}$ to be 3 in spite of the fact that the correct one is 20 (see Appendix C)

uses the wrong radiological equivalence multiplication factor of 3 . If one applies, however, the correct multiplication factor of 20 instead, the effect of the ${ }^{134} \mathrm{Cs}$ release contributes $50 \%$ of that of ${ }^{137} \mathrm{Cs}$ and contributes more than ${ }^{131} \mathrm{I}$ itself. Therefore, the (second) author would like to recommend re-evaluating the past accident including ${ }^{134} \mathrm{Cs}$.

\subsubsection{Contamination and Environmental Cleanup}

The ambient dose rate, surface dose rate, and radioactivity in the soil have been measured around the site after the accident. The detailed distribution maps of the radiation dose are made with a smaller mesh on June 6-14, and June 27-July 8, 2011 [22]. Figure 3.14 indicates that massive amounts of radiation fell to the surface of the ground by snowfall after the plume, which contained radioactive materials released by the rupture at $1 \mathrm{~F} 2$ (suspected), and had been transported to the northwest by wind from the southeast. Although ${ }^{131}$ I with a half-life of 8 days was predominant in the early stage, ${ }^{134} \mathrm{Cs}(2.06 \mathrm{y}),{ }^{137} \mathrm{Cs}(30 \mathrm{y})$, and ${ }^{129 \mathrm{~m}} \mathrm{Te}(33.6 \mathrm{~d})$ are now the main reactive materials. ${ }^{137} \mathrm{Cs}$ with a half-life of 30 years will be a major target for cleanup in the future.

The radioactive materials absorbed by particles in the air are detected by dust sampling at various points in and out of the site. ${ }^{89} \mathrm{Sr}(50.5 \mathrm{~d})$ and ${ }^{90} \mathrm{Sr}(29 \mathrm{y})$ are detected in the soil within a range of $20 \mathrm{~km}$ from the site. These elements have a value range between $1 / 10$ and 1/10,000 that of Cs. These elements may be evidence of the fact that they were released in this accident because the half-life of ${ }^{89} \mathrm{Sr}$ is as short as 50.5 days. Moreover, ${ }^{140} \mathrm{La},{ }^{95} \mathrm{Nb}$, and ${ }^{110 \mathrm{~m}} \mathrm{Ag}$ have been detected slightly in the soil toward the northwest at a distance of $30 \mathrm{~km}$ from the site. A small amount of 


\section{Aerial Measuring Results} Joint US / Japan Survey Data

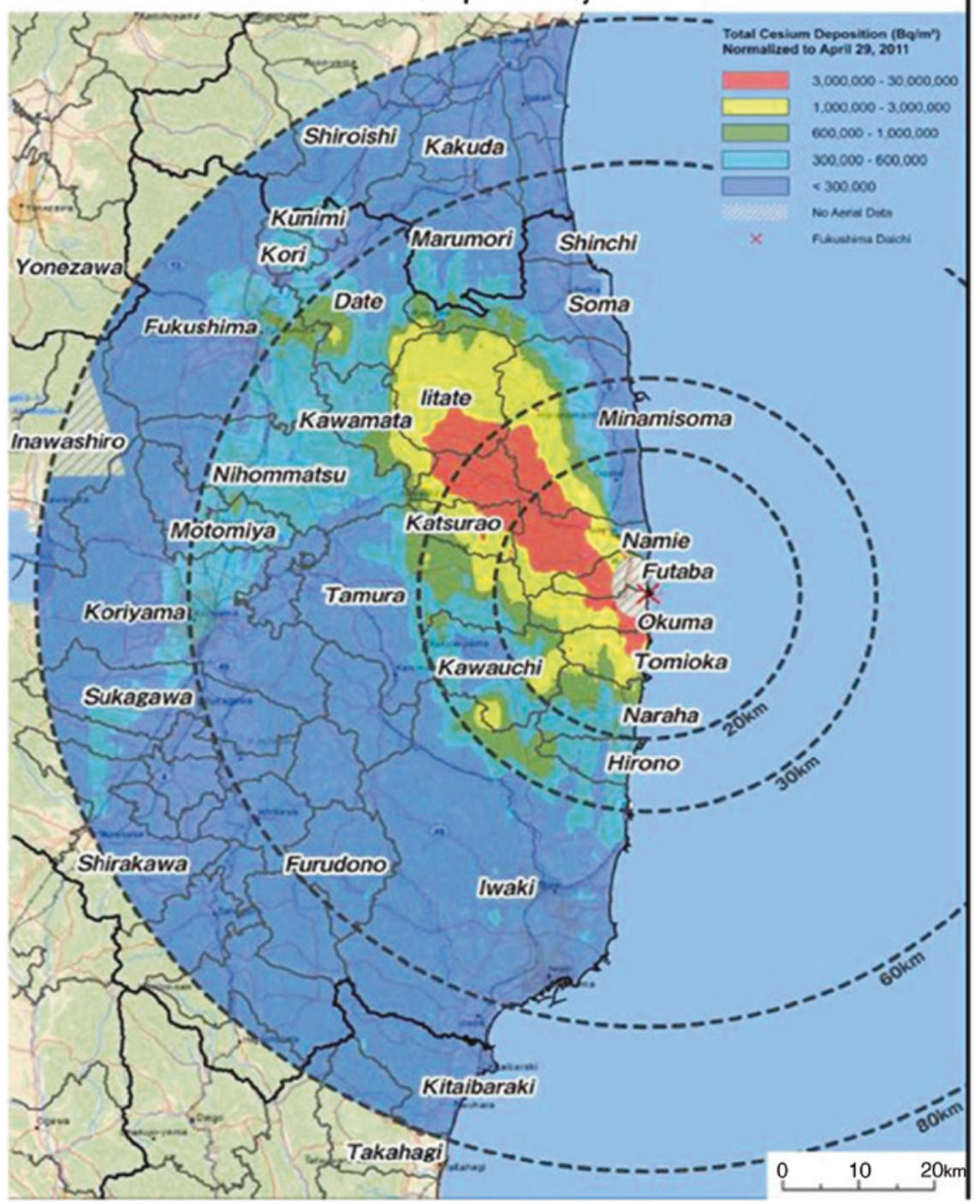

Fig. 3.14 Map of deposition of radioactive cesium (sum of ${ }^{134} \mathrm{Cs}$ and ${ }^{137} \mathrm{Cs}$ ) for the land area within $80 \mathrm{~km}$ of the Fukushima Daiichi plant, reported by MEXT [22]

$\mathrm{Pu}$ isotopes was detected and the evaluation of the isotope ratio ${ }^{238} \mathrm{Pu} /\left({ }^{239} \mathrm{Pu}+{ }^{240} \mathrm{Pu}\right)$ indicated that some samples contained released $\mathrm{Pu}$ by this accident. MEXT reports that the difference in behavior of these elements might account for the wide range of detected values and suggests that more detailed investigation is needed.

The amount of released $\mathrm{Sr}$ and $\mathrm{Pu}$ is estimated to be much less than that of the Chernobyl accident in which contamination by $\mathrm{Sr}$ and $\mathrm{Pu}$ was a severe problem. 
Fig. 3.15 Becquerel Ratio of ${ }^{90} \mathrm{Sr} /{ }^{137} \mathrm{Cs}[\%]$ as a function of the distance from 1F. Color of dots corresponds to the latitude, but no clear tendency has been observed. Data from [23]

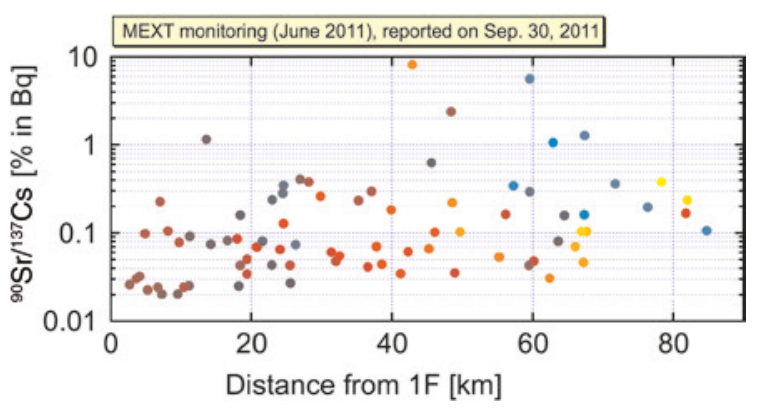

Specifically, the highest value of ${ }^{90} \mathrm{Sr} /{ }^{137} \mathrm{Cs}$ was $8.2 \%$ for the sample obtained at Sōma City, but on average, it was about $0.37 \%$ regardless of the location [23], as shown in Fig. 3.15. Simple scaling of the radiological equivalence of averaged ${ }^{90} \mathrm{Sr}$ release yields about $0.7 \mathrm{PBq}$ from analysis in both Sects. 3.1 and 3.2.2 $(=10$ $\mathrm{PBq} \times 0.37 \% \times 20)$, that is much smaller than that for the Chernobyl accident of $160 \mathrm{PBq}\left({ }^{131} \mathrm{I}\right.$-eq. $)$, where ${ }^{90} \mathrm{Sr} /{ }^{137} \mathrm{Cs}$ was $1 / 10$.

Monitoring of radioactivity under the sea has been executed. Although concentration of radioactivity at a sampling point within the harbor of the nuclear power plant was high because highly concentrated radioactive water was released from the concrete near the sluice gate of $1 \mathrm{~F} 2$ (i.e., ${ }^{131} \mathrm{I} 2.8 \times 10^{15} \mathrm{~Bq},{ }^{134} \mathrm{Cs}$ $9.4 \times 10^{14} \mathrm{~Bq},{ }^{137} \mathrm{Cs} 9.4 \times 10^{14} \mathrm{~Bq}$ ), concentrations outside the plant, especially in the area at a distance of more than $30 \mathrm{~km}$ from the plant, was low [11].

The mechanism of soil contamination by Cs depends on the fraction of it absorbed on the outer surface of minerals or on the layer structure of clay. While an effective method for desorption of Cs from clay has not yet been found, it is expected in the future. Various ways of cleanup of paddy soils should be taken depending on the level of contamination: stripping surface soil, elimination of clay particles by plowing, and removal of vegetation. Effective decontamination methods for soil, which includes methods for disposal of secondary waste, are essential for allowing the return of evacuated residents to their homes if the evacuation zone is to be reopened. For secondary waste from decontamination, temporary keeping, interim storage, and final disposal are required depending on the radiation level. Communication among stakeholders, residents, local governments, and the central government is crucial in the process of determining sites to locate this waste. Academic societies should play an important role by supplying scientific information on RI behavior and safety evaluation for storage and disposal.

\subsection{Summary and Conclusion}

We have seen that the release of radionuclides is subject to the physical and chemical properties and composition of the fuel core, which is highly dependent on its temperature. The source term can be evaluated by the fraction of the release to the environment. The integrated source term can also be evaluated alternatively based 
on radiation monitoring by assuming the fraction of the land deposition, or by making use of atmospheric simulation. Although the exact value of the radioactive release has considerable ambiguity, the amount of the release derived from these methods is roughly consistent, and is considerably less than that released by the Chernobyl accident.

The atmospheric diffusion/transport mechanism of each nuclide has not yet been fully understood. However, in the present situation, Cs is considered to be the most serious radionuclide while the other nuclides may have minor effects on the environment. The environmental behavior of each species must still be investigated from both scientific and political points of view to find a better roadmap for decontamination procedures.

Acknowledgments The authors wish to acknowledge Dr. Takuji Oda for providing data based on the ORIGEN code, and Ms. Ayumi Ito for support in compiling data.

\section{Appendix A: Pasquill-Gifford Dispersion Diagrams}

The diffusion parameters in Eq. (3.2), $\sigma_{y}$ and $\sigma_{z}$, are functions of distance from the source in the $x$ direction. The Pasquill-Gifford curves (Fig. 3.5) are constructed from observations over smooth terrain and represent averages over a few minutes [7]. In practical calculation, the parameter $\sigma_{i}(i=y, z)$ can be approximated as a function of the distance $x[\mathrm{~m}]$,

$$
\sigma_{i}=\gamma_{i} \cdot x^{\alpha_{i}}
$$

where $\gamma_{i}$ and $\alpha_{i}$ are the constants indicated for the stability classes and $x$ [24]. Figure 3.5 is plotted using Eq. (3.8). The stability is classified (as shown in Tables 3.6 and 3.7) by tendency of diffusion into unstable (A-C), neutral (D) and stable (E-F). In Japan, stability class $\mathrm{G}$, which means extremely stable, is added to the existing classes $\mathrm{A}-\mathrm{F}$.

\section{Appendix B: Flash Boiling of Water}

Water tends to condense more at higher pressures. The saturated vapor $P_{\text {sat }}$ [atm] above $1 \mathrm{~atm}$ can be empirically approximated as a function of the temperature $T$ $\left[{ }^{\circ} \mathrm{C}\right]$ by the Antoine equation proposed in 1888 ,

$$
\log P_{\text {sat }}=C_{0}-C_{1} /\left(C_{2}+T\right)
$$

where $\left\{c_{0}, c_{1}, c_{2}\right\}$ are $\{8.07131,1,730.63,233.426\}$ for $1<T<100$, while $\{8.14019,1,810.94,244.485\}$ for $99<\mathrm{T}<374$. 
Table 3.6 Approximation constant for $\sigma_{y}$

\begin{tabular}{l|l|l|l}
\hline Stability & $\alpha_{y}$ & $\gamma_{y}$ & $x(\mathrm{~m})$ \\
\hline \multirow{4}{*}{ A } & 0.901 & 0.426 & $0-1,000$ \\
\cline { 2 - 4 } & 0.851 & 0.602 & $1,000-$ \\
\hline \multirow{2}{*}{ C } & 0.914 & 0.282 & $0-1,000$ \\
\cline { 2 - 4 } & 0.865 & 0.396 & $1,000-$ \\
\hline D & 0.924 & 0.1772 & $0-1,000$ \\
\cline { 2 - 4 } & 0.885 & 0.232 & $1,000-$ \\
\hline \multirow{2}{*}{ E } & 0.929 & 0.1107 & $0-1,000$ \\
\hline \multirow{2}{*}{ F } & 0.889 & 0.1467 & $1,000-$ \\
\hline \multirow{2}{*}{ G } & 0.921 & 0.0864 & $0-1,000$ \\
\cline { 2 - 4 } & 0.897 & 0.1019 & $1,000-$ \\
\hline & 0.929 & 0.0554 & $0-1,000$ \\
\cline { 2 - 4 } & 0.889 & 0.0733 & $1,000-$ \\
\hline & 0.921 & 0.0380 & $0-1,000$ \\
\hline & 0.896 & 0.0452 & $1,000-$ \\
\hline
\end{tabular}

Table 3.7 Approximation constant for $\sigma_{z}$

\begin{tabular}{l|l|l|l}
\hline Stability & $\alpha_{z}$ & $\gamma_{z}$ & $x(\mathrm{~m})$ \\
\hline \multirow{4}{*}{$\mathrm{A}$} & 1.122 & 0.0800 & $0-300$ \\
\cline { 2 - 4 } & 1.514 & 0.00855 & $300-500$ \\
\cline { 2 - 4 } & 2.109 & 0.000212 & $500-$ \\
\hline B & 0.964 & 0.1272 & $0-500$ \\
\cline { 2 - 4 } & 1.094 & 0.0570 & $500-$ \\
\hline D & 0.918 & 0.1068 & $0-$ \\
\hline \multirow{2}{*}{ E } & 0.826 & 0.1046 & $0-1,000$ \\
\cline { 2 - 4 } & 0.632 & 0.400 & $1,000-10,000$ \\
\hline \multirow{2}{*}{ F } & 0.555 & 0.811 & $10,000-$ \\
\hline & 0.788 & 0.0928 & $0-1,000$ \\
\cline { 2 - 4 } & 0.565 & 0.433 & $1,000-10,000$ \\
\cline { 2 - 4 } & 0.415 & 1.732 & $10,000-$ \\
\hline \multirow{2}{*}{ G } & 0.784 & 0.0621 & $0-1,000$ \\
\cline { 2 - 4 } & 0.526 & 0.370 & $1,000-10,000$ \\
\cline { 2 - 4 } & 0.323 & 2.41 & $10,000-$ \\
\hline & 0.794 & 0.0373 & $0-1,000$ \\
\cline { 2 - 4 } & 0.637 & 0.1105 & $1,000-2,000$ \\
\cline { 2 - 4 } & 0.431 & 0.529 & $2,000-10,000$ \\
\cline { 2 - 4 } & 0.222 & 3.62 & $10,000-$ \\
\hline
\end{tabular}

In 1993, Wagner and Pruss [25] proposed the equation that is valid for $0.01 \leq T<374{ }^{\circ} \mathrm{C}$ as:

$\log P_{\text {sat }}=217.755 \times\left(c_{0} \tau^{1}+c_{1} \tau^{1.5}+c_{2} \tau^{1.5}+c_{3} \tau^{3}+c_{4} \tau^{3.5}+c_{4} \tau^{4}+c_{6} \tau^{7.5}\right) /(1-\tau)$ 
Fig. 3.16 Saturated vapor pressure by Wagner's equation

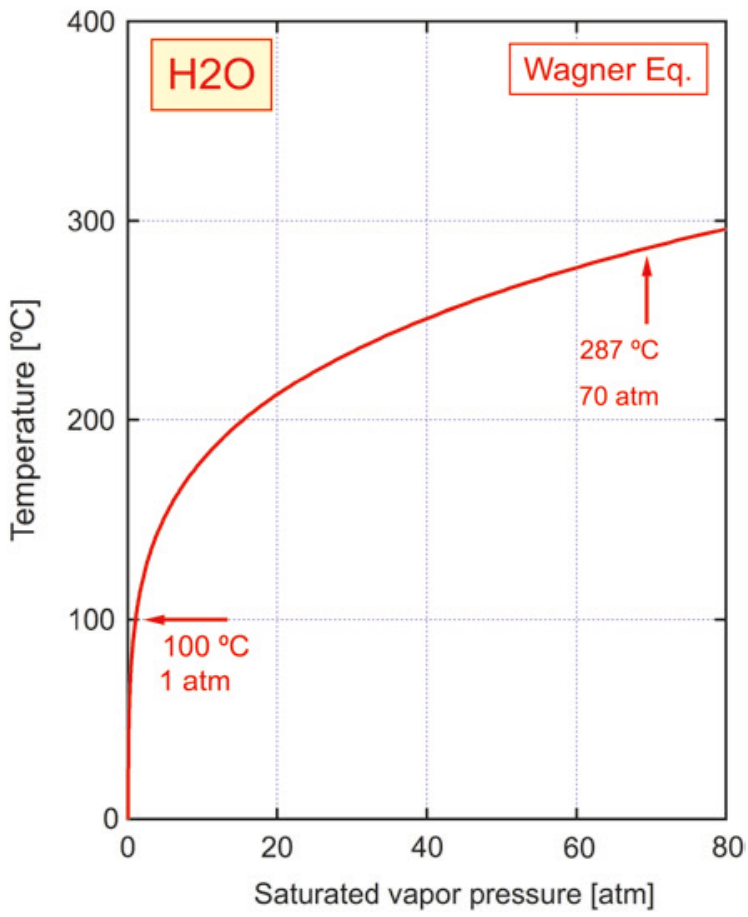

where $\tau=1-(T+273.15) / 647.096$ and $\left\{c_{0}, c_{1}, c_{2}, c_{3}, c_{4} c_{5}, c_{6}\right\}$ are $\{-7.85951783$, $1.84408259,-11.7866497,22.6807411,-15.9618719,1.80122502\}$.

This function form is more useful in that the coefficients are usable over the range from the experimentally given triple point and the critical point, and that this form also copes well with its derivatives. Thus, it has been approved by the International Association for the Properties of Water and Steam. Other various formulas can be found in Ref. [26].

The calculated result of $T$ as a function of $P_{\text {sat }}$ is shown in Fig. 3.16. For example, the sudden decrease of pressure, say from 70 to $1 \mathrm{~atm}$, by valving on the SRV, leads to a sudden drop in the vaporization temperature from 290 to $100{ }^{\circ} \mathrm{C}$. As a result, quite rapid evaporation of the water, called "flash boiling," in the RPV might occur. Therefore, water injection needs to be started at the same time as, or at least as soon as, the SRV is opened.

\section{Appendix C: Ground Shine of Gamma Ray Radiation}

\section{C.1 Half-Value Layer}

External exposure from the contaminated ground is called "ground shine." The required database is compiled in [27]. Due to absorption/scattering by air, the radiation was attenuated. The characteristic lengths at which the radiation becomes 
half, the half-value layer (HVL), of lead, iron, aluminum, water, air, and concrete are compiled in Table E2 of Ref. [27].

Roughly speaking, the dose rate from ground shine reflects the area inside the circle of several times the air HVL in the radius. Each point of Figs. 3.12 and 3.15 represents at least 4.57 or $4 \mathrm{~km}^{2}$, respectively. Therefore, the influence of one area on adjacent points in the MEXT monitoring that could cause a double-counting of the dose rate are eliminated.

\section{C.2 Dose Factor}

Conversion factors from $\left[\mathrm{Bq} / \mathrm{m}^{2}\right]$ to $[\mathrm{Sv} / \mathrm{h}]$ listed in Table E3 [27] include effective dose rate for external dose and committed inhalation due to resuspension resulting from remaining on contaminated ground. However, since the inhalation dose for the present situation is considerably small, this database can also be used for the pure external dose.

The shielding factor $(S F)$ needs to be considered, since the evaluation above is the ideal case where the ground is smoothly spread over the infinite disk. For ordinary ground cases, Ref. [27] proposed using SF of 0.47-0.85 (representative of 0.7). In addition, the dose factors for plume submersion, crucial in the early stage of accidents, is calculated in Table 3.1 of Ref. [28].

\section{C.3 Radiological Equivalence}

Radiological equivalence is the ratio of the activity released of a specified radionuclide to the case for ${ }^{131} \mathrm{I}$. This value is used to classify the scale of the accident as described in [29]. It considers the above mentioned ground contamination and plume submersion. The database for the total effect on the public is given in Table 15 in Appendix I of Ref. [29].

Data are listed in Table 3.8 for species of interest. Although ${ }^{134} \mathrm{Cs}$ is the present leading radiator, ${ }^{137} \mathrm{Cs}$ is the most crucial nucleus in the evaluation of the rating of the accident. Evaluation of ${ }^{90} \mathrm{Sr}$ is less effective due to both its low concentration (approximately below $1 \%$ of ${ }^{137} \mathrm{Cs}$ ) and its low radiological equivalence (half of $\left.{ }^{137} \mathrm{Cs}\right)$.

It should be noted that the official data of ${ }^{131} \mathrm{I}$ eq. of ${ }^{134} \mathrm{Cs}$ has significant error. This is caused by the significant error of the 50 years dose factor for ${ }^{134} \mathrm{Cs}$ tabulated in Table E3 in [27]. The correct value is 5.1E-02 rather than 5.1E-03.

This error has been taken into account in the International Nuclear and Radiological Event Scale (INES) defined in [29]. As a result, the radiological equivalence to ${ }^{131}$ I summarized in Table 2 of the INES user guide, I-eq, for ${ }^{134} \mathrm{Cs}$ has been under-estimated to $2.8(\sim 3)$ which, in reality, should be 16.2 ( 20). 
Table 3.8 Dataset to assess radiological equivalence to ${ }^{131} \mathrm{I}$

\begin{tabular}{l|l|l|l|r}
\hline Nucleus & $\tau$ & Air HVL $(\mathrm{m})$ & $(\mathrm{Sv} / \mathrm{h}) /\left(\mathrm{Bq} / \mathrm{m}^{2}\right)$ & ${ }^{131} \mathrm{I}$ eq. \\
\hline${ }^{131} \mathrm{I}$ & $8.0 \mathrm{~d}$ & 55.9 & $1.30 \mathrm{E}-12$ & 1 \\
\hline${ }^{134} \mathrm{Cs}$ & $2.06 \mathrm{y}$ & 71.9 & $5.40 \mathrm{E}-12$ & $3 \rightarrow 20$ \\
\hline${ }^{137} \mathrm{Cs}$ & $50 \mathrm{y}$ & 69.2 & $2.10 \mathrm{E}-12$ & 40 \\
\hline${ }^{89} \mathrm{Sr}$ & $50.5 \mathrm{~d}$ & 80.5 & $8.0 \mathrm{E}-15$ & 0.5 \\
\hline${ }^{90} \mathrm{Sr}$ & $29.1 \mathrm{y}$ & - & $1.0 \mathrm{E}-15$ & 20 \\
\hline
\end{tabular}

Note: The second author noticed this mistake and sent a letter to MEXT and to the Nuclear Regulation Authority in October 2012 [30]. MEXT sent it to the IAEA through diplomatic channels. Finally, after several reminders, the IAEA issued the corrigendum of Refs. [27, 29] in March 2013. Now I-eq for ${ }^{134}$ Cs has been corrected to 17 in Table 2 of [29]. Tables 15 and 16 have yet to be corrected; they should be 17 and 20 (1 digit), respectively.

\section{C.4 Experimental Determination of the Shielding Factor (SF)}

Assessment of the relationship between the ground contamination and the resultant ambient dose rate needs careful consideration of the definition of the quantity used in the database.

In order to clarify the definition, we described the relation in the Eq. (3.11) as:

$$
\frac{D}{H^{*}(10) / K}=A \cdot C F_{g r d}(w / o G R E) \cdot S F_{t o t} \cdot \frac{1}{H^{*}(10) / K}
$$

The dose factor $C F_{\text {grd }}$ represents the ambient dose rate at $1 \mathrm{~m}$ above ground level per unit of deposition for a radionuclide. In the most commonly used database [27], this factor is calculated using the RASCAL code (ver. 3.0.5), considering a ground roughness factor (GRF) of 0.7 , considering ordinary ground (Eq. 3.12). Note that GRF $=1$ corresponds to the case for a smooth infinite field of lawn. Shielding factor is defined by the Kerma in the shielding material divided by the Kerma for the infinite smooth surface (Eq. 3.13).

$$
\begin{aligned}
C F_{\text {grd }}(w / G R F) & =C F_{\text {grd }}(w / o G R F) \cdot G R F \\
S F_{t o t} & =G R F \cdot S F_{B L G}
\end{aligned}
$$

Therefore, the practical formula to be used can be written as

$$
\frac{D}{H^{*}(10) / K}=A \cdot C F_{g r d}(w / G R E) \cdot S F_{B L G} \cdot \frac{1}{H^{*}(10) / K}
$$


Fig. 3.17 Measured dose rates assuming $1 \mathrm{~Sv} / \mathrm{h}=1 \mathrm{~Gy} / \mathrm{h}$ versus those evaluated from the ground shine with $\mathrm{GRF}=0.7$. Background dose rate of $0.06 \mu \mathrm{Sv} / \mathrm{h}$ was assumed

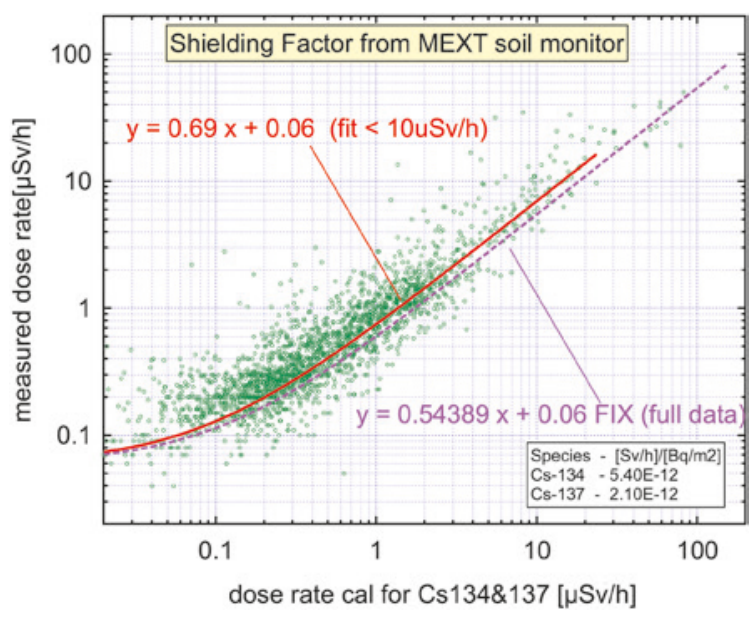

$H^{*}(10) / K$ is the conversion factor from Kerma [Gy] to $1 \mathrm{~cm}$ ambient dose equivalent $[\mathrm{Sv}]$, for which a typical value of 1.3 following the data tabulated in Ref. [31] might be a plausible approximation for sub-MeV photon.

Note that for the emergency situation, $1 \mathrm{~Gy} / \mathrm{h} \approx 1 \mathrm{~Sv} / \mathrm{h}$, is usually proposed and the data provided for the accident has been provided in this approximation. Therefore, it is necessary to treat the measured dose rate as the form of $(D / 1.3)$ (Gy/h).

$$
\left(\frac{D}{1.3}\right)=A \cdot C F_{g r d} \cdot \frac{S F_{B L G}}{1.3}
$$

The shielding factor can also be evaluated by comparing the dose rate calculated from the measured ground contamination using Eq. (3.14) with the measured dose rate, as shown in Fig. 3.17. In the fitting procedure, we fixed the baseline corresponding to the background natural radiation dose.

One can see that the $\left(S F_{B L D} / 1.3\right)=0.7$, by fitting where dose rate $<10 \mu \mathrm{Sv} / \mathrm{h}$ (adopted because of the large number of data points), is a plausible value in the general discussion, which corresponds to $S F_{B L D}=0.9$. Because the scattering of data is considerably large, it may be misleading if one calculates external exposure from the local ground contamination. The dose rate used was the averaged, namely effective, value around the measurement point.

The inverse determination of the ground contamination from the measured dose rate can be evaluated as

$$
A=\left(\frac{D}{1.3}\right) \cdot C F_{g r d}^{-1} \cdot\left(\frac{S F_{B L G}}{1.3}\right)^{-1}
$$

where the experimental value of $\left(S F_{B L D} / 1.3\right)=0.7$ can be used. 
Open Access This chapter is distributed under the terms of the Creative Commons Attribution Noncommercial License, which permits any noncommercial use, distribution, and reproduction in any medium, provided the original author(s) and source are credited.

\section{References}

1. Groff A (1983) OriGEN-2: a versatile computer code for calculating the nuclear compositions and characteristics of nuclear materials. Nuclear Technology 62:335-352

2. Lewis BJ, Dickson R, Iglesias FC, Ducros G, Kudo T (2008) Overview of experimental programs on core melt progression and fission product release behavior. J Nucl Mater 380:126-143

3. Nuclear Safety Research Association (2013) The behaviors of the light water reactor fuel 5th ed. (in Japanese). Nuclear Safety Research Association, Tokyo

4. Lorenz RA, Osborne MF (1995) A summary of ORNL fission product release test with recommended release rates and diffusion coefficients. NUREG/CR-6261. Oak Ridge National Laboratory, Oak Ridge

5. Vierow K, Liao Y, Johnson J, Kenton M, Gauntt R (2004) Severe accident analysis of a PWR station blackout with the MELCOR, MAAP4 and SCDAP/RELAP5 codes. Nuclear Engineering and Design 234: 129-145

6. Ujita H, Satoh N, M. Naitoh M, Hidaka M, Shirakawa N, Yamagishi M (1999) Development of severe accident analysis code SAMPSON in IMPACT project. J Nucl Sci and Tech 36:1076-1088

7. Panofsky HA, Dutton JA (1984) Atmospheric turbulence-Models and methods for engineering applications. John Wiley \& Sons Inc, New York

8. Chino M, Ishikawa H, and Yamazawa H (1993) SPEEDI and WSPEEDI: Japanese emergency response systems to predict radiological impacts in local and workplace areas due to a nuclear accident. Radiat Prot Dosimetry 50:145-152

9. Terada H, Chino M (2008) Development of an atmospheric dispersion model for accidental discharge of radionuclides with the function of simultaneous prediction for multiple domains and its evaluation by application to the Chernobyl nuclear accident. J Nucl Sci and Tech 45:920-931

10. Tokyo Metropolitan Institute of Public Health (2011) Radioactive material level of fallout in Tokyo (in Japanese). Available at: http://monitoring.tokyo-eiken.go.jp/monitoring/f-past_ data.html. Accessed July 2011

11. Nuclear Emergency Response Headquarters, Government of Japan (2011) Report of the Japanese government to the IAEA ministerial conference on nuclear safety-The accident at TEPCO's Fukushima Nuclear Power Stations-. Available at: http://www.kantei.go.jp/ foreign/kan/topics/201106/iaea_houkokusho_e.html. Accessed 11 June 2011

12. Chino M, Nakayama H, Nagai H, Terada H, Katata G Yamazawa H (2011) Preliminary estimation of release amounts of ${ }^{131} \mathrm{I}$ and ${ }^{137} \mathrm{Cs}$ accidentally discharged from the Fukushima Daiichi Nuclear Power Plant into the atmosphere. J Nucl Sci and Tech 48:1129-1134

13. Japan Institute of International Affairs (2011) Center for the Promotion of Disarmament and Non-Proliferation. Available at: http://www.cpdnp.jp/eng/English/. Accessed July 2011

14. Survey results by Japan Chemical Analysis Center (2011) Dose rate report by Japan Chemical Analysis Center (in Japanese). Available at: http://www.jcac.or.jp/ site/senryo/senryo-kakushu.html. Accessed 11 July 2011

15. Nuclear Regulation Authority (2011) Dose rate report within a radius of $20 \mathrm{~km}$ from Fukushima Daiichi Nuclear Power Station (in Japanese). Available at: http://radioactivity.nsr. go.jp/ja/contents/4000/3633/24/1305284_0421.pdf. Accessed 11 July 2011.

16. Fukushima Prefecture (2011) Dose rate report by Fukushima prefecture 5-7 April 2011 (in Japanese). Available at: http://www.pref.fukushima.jp/j/schoolmonitamatome.pdf. Accessed July 2011 
17. Kawamura H, Kobayashi T, Furuno A, In T, Ishikawa Y, Nakayama T, Shima S, Awaji T (2011) Preliminary numerical experiments on oceanic dispersion of ${ }^{131} \mathrm{I}$ and ${ }^{137} \mathrm{Cs}$ discharged into the ocean because of the Fukushima Daiichi Nuclear Power Plant Disaster. J Nucl Sci and Tech 48:1349-1356

18. Morino Y, Ohara T, Nishizawa M (2011) Atmospheric behavior, deposition, and budget of radioactive materials from the Fukushima Daiichi nuclear power plant in March 2011. Geophysical Research Letters 38:L00G11

19. Ministry of Education, Culture, Sports, Science and Technology (2011) Analysis report of soil radionuclide (Cs-134 and Cs-137) (in Japanese). Available at: http://www.mext.go.jp/b_ menu/shingi/chousa/gijyutu/017/shiryo/_icsFiles/afieldfile/2011/09/02/1310688_1.pdf. Accessed 11 July 2011

20. Ministry of Education, Culture, Sports, Science and Technology (2011) On the mapping of radiocesium concentration in soil (in Japanese). Available at: http://www.mext.go.jp/b_menu /shingi/chousa/gijyutu/017/shiryo/_icsFiles/afieldfile/2011/09/02/1310688_2.pdf, and http:// radioactivity.nsr.go.jp/ja/contents/6000/5047/24/5600_110921_rev130701.pdf._Accessed Sept 2011

21. Tokyo Metropolitan Institute of Public Health (2011) Radioactive material level of fallout in Tokyo (in Japanese). Available at: http://monitoring.tokyo-eiken.go.jp/monitoring/f-past_ data.html. Accessed July 2011

22. Nuclear Regulation Authority (2011) Results of airborne monitoring by the Ministry of Education, Culture, Sports, Science and Technology and the U.S. Department of Energy (in Japanese). Available at: http://radioactivity.nsr.go.jp/en/contents/4000/3180/24/1304797_050 6.pdf. Accessed July 2011

23. Ministry of Education, Culture, Sports, Science and Technology in Japan (2011) Radionuclide analysis for plutonium and strontium by MEXT (in Japanese). Available at: http://radioactivity.nsr.go.jp/ja/contents/6000/5048/24/5600_110930_rev130701.pdf. Accessed Oct 2011

24. The Environment Agency of Japan (1993) Manual for total volume control of nitrogen oxide (in Japanese)

25. Wagner W, Pruss A (1993) International equations for the saturation properties of ordinary water substance. Revised according to the international temperature scale of 1990. Addendum to Journal of Physical and Chemical Reference Data 16, 893 (1987). J. Phys. Chem. Ref. Data 22: 783-787

26. Murphy DM, Koop T (2005) Review of the vapour pressures of ice and supercooled water for atmospheric applications. Quarterly Journal of the Royal Meteorological Society 131:1539-1565

27. International Atomic Energy Agency (2000) Generic procedures for assessment and response during a radiological emergency, IAEA-TECDOC-1162. http://www-pub.iaea.org/mtcd/publi cations/pdf/te_1162_prn.pdf. Accessed July 2011

28. Eckerman KF, Ryman JC (1993) External exposure to radionuclides in air, water, and soil. Federal Guidance Report No. 12, EPA-402-R-93-081, Oak Ridge National Laboratory. http://nnsa.energy.gov/sites/default/files/seis/fgr12.pdf. Accessed July 2011

29. International Atomic Energy Agency (2009) The international nuclear and radiological event scale user's manual 2008 edition. http://www-pub.iaea.org/MTCD/ publications/PDF/INES-2009_web.pdf. Accessed July 2011

30. Kado S, Endo T (2012) Report on the mistakes in the dose factor in IAEA-TECDOC-1162 and its impact on the assessment for the Fukushima Nuclear Power Plant accident, letter to MEXT (Oct. 24, 2012, in Japanese; Nov. 7, 2012 English translation)

31. International Commission on Radiological Protection (1997) Conversion coefficients for use in radiological protection against external radiation 74 . Elsevier 